\title{
Investigating Evaluation Frameworks for Electronic Health Record: A Literature Review
}

\author{
Zahra Ebnehoseini ${ }^{1}$, Hamed Tabesh ${ }^{2}$, Majid Jangi ${ }^{3}$, Kolsoum Deldar ${ }^{4}$, Sayyed Mostafa Mostafavi ${ }^{2}$, Mahmood Tara * \\ ${ }^{1}$ Department of Medical Informatics, Psychiatry and Behavioral Sciences Research Center, Mashhad University of Medical \\ Sciences, Mashhad, Iran; ${ }^{2}$ Department of Medical Informatics, Faculty of Medicine, Mashhad University of Medical Sciences, \\ Mashhad, Iran; ${ }^{3}$ Department of Medical Informatics, Health Information Technology Research Center, Isfahan University of \\ Medical Sciences, Isfahan, Iran; ${ }^{4}$ Department of Medical Informatics, School of Medicine, Shahroud University of Medical \\ Sciences, Shahroud, Iran
}

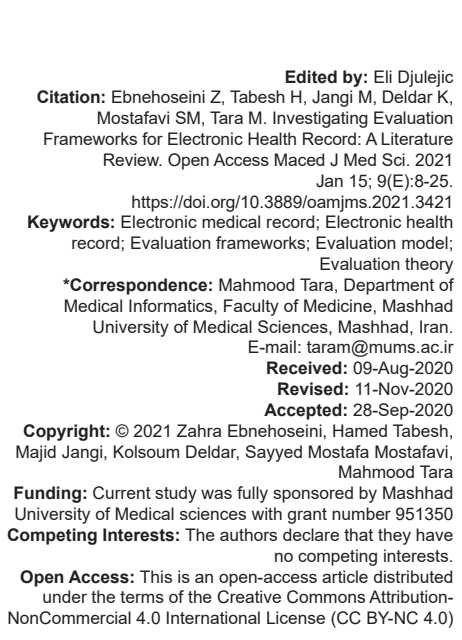

\section{Introduction}

In recent years, electronic health records (EHRs) have been adopted by an ever-increasing number of health-care organizations around the world. Subsequently, assessment of the quality of performance ofEHRs is currently the subject of extensive research and debate. Evaluation is defined as the "act of measuring or exploring properties of a health information system (in planning, development, implementation, or operation), the result of which informs a decision to be made concerning that system in a specific context" [1]. The adoption or development of an evaluation framework is the standard method for EHR evaluation. Evaluation frameworks are defined as "methodologies that capture the processes integral to information systems, the users and the world in which the users' function" [2].

Various frameworks have been proposed in different studies for EHR evaluation [3]. Each evaluation framework has unique features and provides a different perspective to assess various aspects of the EHR. The focus of evaluation frameworks may be on the user's behavioral features, organizational aspects, social factors, or technological characteristics. For example, the technology acceptance model (TAM) [3], [4], [5] and the unified theory of acceptance and use of technology (UTAUT) [6] are adopted in many studies for EHR evaluation. TAM was proposed by Davis et al. in 1989. It was developed to predict individual adoption and use of new information technologies (IT) [7]. UTAUT was formulated by Venkatesh et al. in 2003 [8]. In UTAUT, social influence indicators can measure social factors in EHR adoption [9]. Another famous framework for EHR evaluation is the information system success model (ISSM) [10]. The goal of the ISSM is an evaluation of system quality, service quality, and information quality [11]. The task-technology fit (TTF) framework measures the level of coherence between user tasks and requirements, on the one hand, and system characteristics on the other [12]. 
Nevertheless, a limited number of studies were performed on the identification and classification of EHR evaluation frameworks. Currie proposed evaluation frameworks for nursing informatics. The frameworks were categorized into four groups: Generic, human behavior, social/organizational relations, and software lifecycle [13]. Yusof et al. classified different dimensions of twenty evaluation frameworks for health information systems into three main categories [14]. Nguyen et al. classified impact and contingency factors in a systematic review. This study did not present a formal review of the underlying theoretical EHR evaluation frameworks based on the selected reviewed articles. Indeed, this has not been addressed in the current literature reviews of EHR evaluation studies [10]. A literature review covering these studies can be used as a reference for researchers.

As mentioned, the diversity of developed evaluation frameworks reflects the variation in the purpose of evaluation. Various evaluation measures can be utilized to serve each framework. The coverage rate of evaluation measures in a common framework may differ in the studies. For example, Holden and Karsh reviewed 16 studies in healthcare that used TAM. Almost all the studies added variables to TAM and proposed a modified TAM in an attempt to better recognize the antecedents of acceptance or health IT-use behavior. Given the fact that there are many frameworks for EHR evaluation, an inclusive literature review that covers all published studies on EHR evaluation is deemed to be essential. However, a comprehensive literature review itself is not enough. Researchers may wish to conduct a comparative study before adopting or developing EHR evaluation frameworks. Hence, a tailored study is needed when the aim is not just to identify the EHR evaluation frameworks but also to compare the frameworks.

As far as we know, no systematic identification of EHR evaluation frameworks has been conducted. As well, no study has been performed to determine the coverage rate of evaluation measures in EHR evaluation frameworks. The current study addressed these gaps. Accordingly, the objectives of the present study are (1) to undertake a comprehensive literature review of studies of EHR evaluation frameworks; (2) to identify and categorize evaluation measure in EHR evaluation frameworks; (3) to propose a method for measuring the coverage rate of evaluation measures in the frameworks; and (4) to determine the coverage rate of evaluation measures in EHR evaluation frameworks.

\section{Methodology}

\section{Acknowledge}

The current study was a part of the doctorate thesis (research plan code: 951350) and was performed according to the following steps:

\section{A literature review on EHR evaluation frameworks, \\ 2. To develop a hierarchical structure for categorizing extracted items from the EHR evaluation frameworks, \\ 3. To determine the coverage rate of evaluation measures in identified studies.}

\section{frameworks \\ The literature review on EHR evaluation}

\section{Search strategy}

A search of English literature from January 2007 to August 2017 in PubMed, Scopus, ScienceDirect, and Cochrane databases was conducted to identify relevant studies. In the present review, a hybrid protocol and search strategy from Sockolow et al. [2], Yusof et al. [14], and other EHR literature reviews were implemented [2], [15], [16], [17]. In our study, ISO's EHR definition was applied. The search criteria focused on EHR evaluation frameworks. To achieve a comprehensive search strategy to identify the EHR evaluation frameworks, a large set of search terms were used. The terms related to EHR were derived from ISO's EHR definition and previous systematic literature reviews on EHR [2], [15], [16], [17]. The terms related to the evaluation frameworks were based on the previous literature reviews [2], [14], [15], [17].

Table 1 shows Mesh terms and keywords related to EHR (Group A) and evaluation frameworks (Group B). The "OR" operator was used to combine keywords in Group A and Group B, separately. Then, results from both groups were combined using the "AND" operator. Furthermore, our search was augmented by reviewing bibliographies from identified studies.

Table 1: Groups of keywords used in the search strategy

\begin{tabular}{|c|c|}
\hline Group A & $\begin{array}{l}\text { Electronic health record and related concept } \\
\text { electronic Health records* } \\
\text { Medical records systems, computerized* } \\
\text { Computerized medical records system } \\
\text { Electronic medical records } \\
\text { Electronic patient record } \\
\text { Hospital information systems* }\end{array}$ \\
\hline Group B & 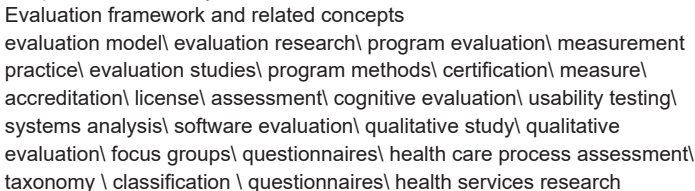 \\
\hline
\end{tabular}

\section{Studies selection criteria}

Throughout our study, we focused on evaluation frameworks that were developed or adopted for the summative EHR evaluation.

The articles that did not focus on EHR evaluation, commentary letters, and summary of articles presented at conferences were excluded from the study. Furthermore, the studies whose evaluation dimensions of framework descriptions were not included by their 
authors as well as studies that focused on frameworks for formative or lifecycle EHR evaluation.

\section{Preliminary data abstraction}

For each studies meeting, the inclusion criteria data were abstracted independently by two researchers (ZE and KD). The researchers kept a list of the reviewed studies that were excluded from the review along with the reasons for their exclusion. Then, full text studies were reviewed and eligible studies were identified and included in the data extraction process. Any disagreement to include an article was resolved by holding a discussion between the two evaluators. Unsolved disagreements were discussed with a third evaluator (MT). The final decision was made after a consensus was reached between all three evaluators. General data abstracted from each study included the framework name, author(s), location, publication date, EHR evaluation purpose(s), healthcare contexts, evaluation scales, participants, and data collection methods. These data were selected based on the previous related literature reviews [10], [14], [18].

\section{To develop a hierarchical structure for} categorizing extracted items from the EHR evaluation frameworks

To classify extracted items from EHR evaluation frameworks, a three-level hierarchical structure was developed. The structure included aspects, dimensions, and evaluation measures. Top level of this hierarchical structure comprised aspects. Each aspect encompassed a number of dimensions. Middle and lower levels of the hierarchy contained dimensions and evaluation measures, respectively. Each evaluation dimension contained at least one evaluation measure.

Yusof et al. investigated the evaluation frameworks for health information systems and suggested that technology, human, and organization are the essential evaluation aspects of health information systems [14]. This study adopted evaluation aspects used by Yusof et al.

The middle level which included eight dimensions was developed in the following two steps. First, a number of literature reviews, related to categorizing evaluation dimensions of EHR, were identified [10], [13], [18]. Evaluation dimensions of three identified literature reviews were extracted independently by two researchers and were mapped in evaluation aspects including, technology, human, and organization. The results were saved in Excel files. An expert panel approach was used to combine the extracted dimensions. The common dimensions were merged by two researchers. Unresolved disagreements were discussed with a third researcher. After this step, eight dimensions were considered as "primary dimensions of the hierarchy structure," which are as follows:

- Technology: System quality, information quality, service quality

- Human: Satisfaction, system use

- Organization: Characteristics of organization and organizational factors, environment, and, net benefit and EHR impacts.

In the second step, evaluation dimensions of identified studies related to EHR evaluation frameworks were extracted independently by two researchers. The results were saved in Excel files. Each researcher compared evaluation dimensions of EHR in the retrieved studies to "primary dimensions of the hierarchy structure." Common dimensions were mapped to "primary dimensions of the hierarchy structure." Some dimensions were added to the hierarchical structure in this step. Then, two Excel files were combined in expert panel meetings that were held by two researchers. In this step, four dimensions were added to the middle level of the hierarchy structure, which includes "computer knowledge and self-efficacy," "users' characteristics and personality," and "positive or negative feeling about EHR." Furthermore, the dimension of "net benefit and EHR impacts" was divided into two separate dimensions as following "effects on workflow and organization" and "effects on outcome quality of care."

The lower level of the hierarchy structure was formed by a similar procedure. Evaluation measures of identified studies related to EHR evaluation frameworks were extracted independently by two researchers and were then mapped in various dimensions of evaluation aspects. Unsolved disagreements were discussed by two researchers. Out of a total of 588 evaluation measures that were extracted from the frameworks, 110 remained after combing common evaluation measures. These evaluation measures covered 12 dimensions in three evaluation aspects. 50, 29, and 31 evaluation measures were related to the aspects of technology, human, and organization, respectively. The number of evaluation measures in the three dimensions was as follows:

- Technology: System quality ( $\mathrm{n}=15)$, information quality $(n=23)$, and service quality $(\mathrm{n}=12)$.

- Human: satisfaction $(n=5)$, system use $(n=9)$, computer knowledge and self-efficacy $(n=2)$, users' characteristics and personality $(n=3)$, and positive or negative feeling about EHR $(n=10)$

- Organization: Characteristics of organization and organizational factors $(n=28)$, "effects on workflow and organization ( $n=1)$, effects on outcome quality of care $(n=1)$, and environment $(n=1)$

Figure 1 shows the hierarchical structure for categorizing extracted items from the EHR evaluation frameworks. 


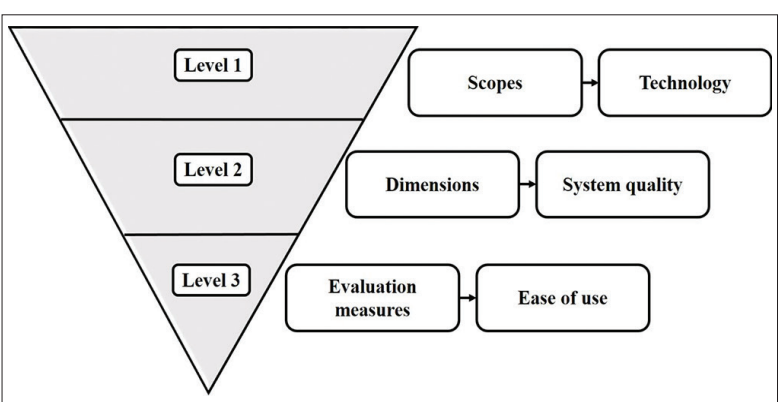

Figure 1: The hierarchical structure for categorizing extracted items from the electronic health records evaluation frameworks

Determining the coverage rate of evaluation measures in identified studies (frameworks)

To determine the coverage rate of evaluation measures in the identified studies, the following six steps were taken:

Step 1- Determination of relative frequency (RF) of evaluation measures in the identified studies:

$\mathrm{RF}$ of an evaluation measure= Frequency of an evaluation measure in the identified studies/Total number of identified studies

Example: RF of "usefulness" evaluation measure $=$ the number of studies that contained this evaluation measure divided by the total number of identified studies.

\section{$38 / 62=0.61$}

Step 2- Determining the sum of RF of the evaluation measures in different dimensions.

Sum of the RF of evaluation measures in each dimension $=$ Total of the RF of evaluation measures in dimensions for all identified studies.

Example: Sum of RF of the "system quality" dimension was equal to the sum of the RF of the following evaluation measures: Ease of use, usefulness, usability, reliability, response time, accessibility, sufficient resources, privacy and security, availability, system function, system interoperability and integration, complexity, flexibility, mobility, and confusion.

$0.61+0.52+0.21+0.21+0.13+0.10+0.19+0.11+$ $0.08+0.06+0.15+0.03+0.02+0.02+0.02=2.45$

Step 3- Determining the sum of RF of the dimensions related to each aspect.

Sum of the RF of the dimensions related to each aspect $=$ Total of the RF of the dimensions related to each aspect for all identified studies.

Example: Sum of RF of the "technology" aspect was equal to the sum of the RF of the following dimensions: system quality, information quality, and service quality.

\section{$2.45+1.44+0.73=4.62$}

Step 4- Determination the sum of RF of the evaluation measures in dimensions and aspects for each identified study
Example: Sum of RF of the dimension of "system quality" for the study by Otieno et al. was equal to the sum of RF of the following evaluation measures: ease of use, usefulness, usability, reliability, and availability.

$$
0.61+0.52+0.08=0.90
$$

Example: Sum of RF of the aspect of "technology" for the study by Otieno et al. was equal to the sum of RF of the following evaluation dimensions: System quality, information quality, and service quality.

$$
0.90+0.72+0.36=1.98
$$

Step 5- Determination of coverage rate of evaluation measures in dimensions and aspects for the identified studies.

The coverage rate of evaluation measures in dimensions/aspects for each identified studies = Sum of RF of evaluation measures in dimensions and aspects for each of the identified studies (the values obtained in Stage 4)/ sum of RF of evaluation measures in dimensions and aspects for the all identified studies (the values obtained in Stages 2 and 3) $\times 100$

Example: Sum of RF of the dimension of "system quality" for the study by Otieno et al. =

$$
(0.90 / 2.45) \times 100=37 \%
$$

Example: Sum of the RF of the "technology" aspect for the study by Otieno et al. =

$$
(1.98 / 4.62) \times 100=44 \%
$$

Step 6- Categorization of coverage rate of evaluation measures in dimensions and aspects for the identified studies.

In this step, the determined rates in step 5 above were categorized as follows:

1. Appropriate coverage ( $50 \% \leq$ coverage rate),

2. Moderate coverage $(25 \% \leq$ coverage rate $<50 \%)$,

3 . Low coverage (coverage rate $<25 \%$ ), and

4. Non-coverage (coverage rate $=0$ ).

After determination of the coverage rate of evaluation measure for the identified studies, the results were plotted on three figures. Using these figures, we can compare different studies.

\section{Results}

\section{Literature review}

The database search was conducted in 2017. A total of 8276 records were retrieved. Among these, 62 studies met the inclusion criteria (Figure 2).

We conducted a review of the characteristics of the 62 eligible studies. A list of different demographic characteristics and research methods is presented in Table 2. 


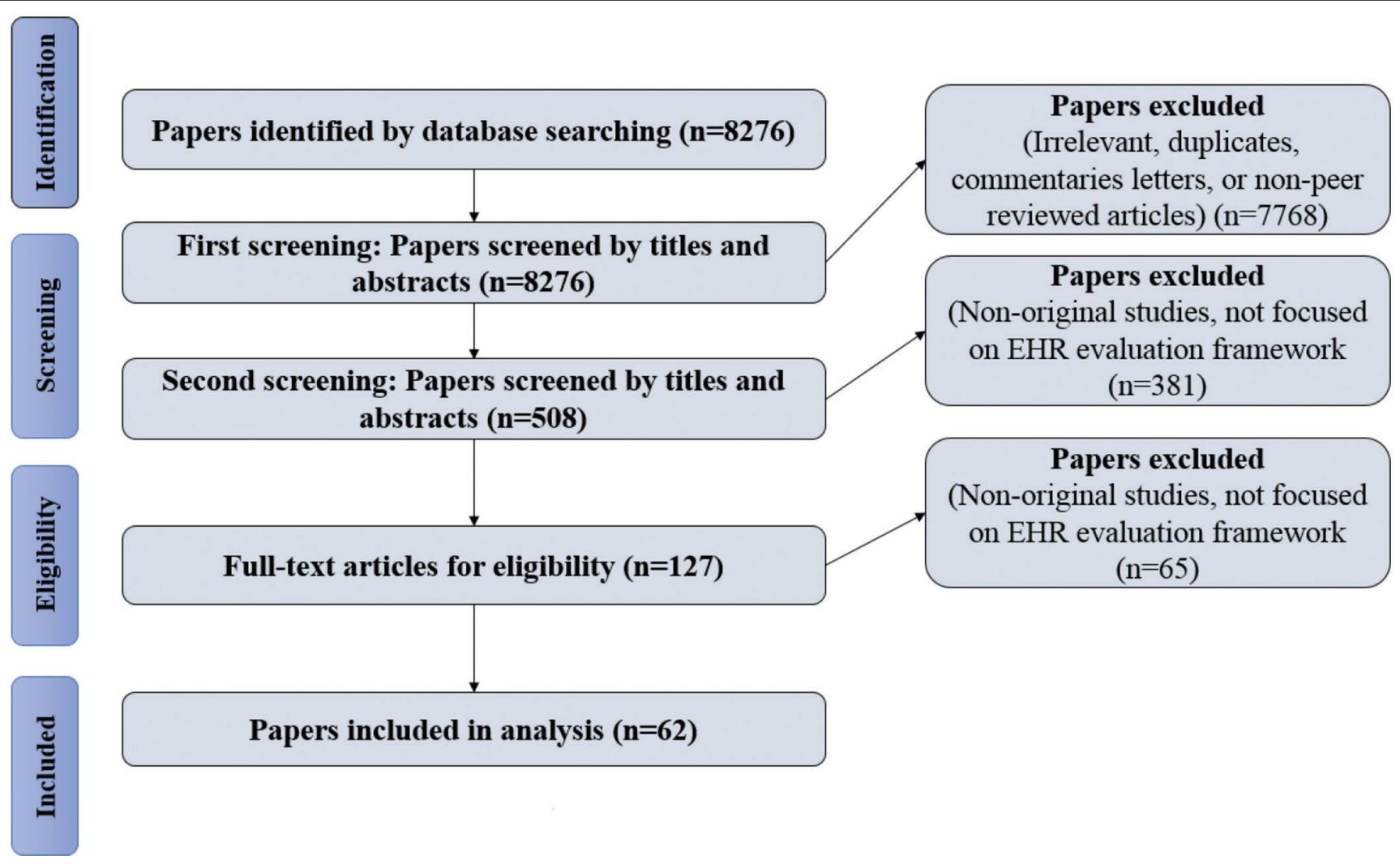

Figure 2: Flow diagram of review

More than half of the studies $(n=32)$ were from the USA and Taiwan. Fourteen studies were from Iran, the UK, Canada, and the Netherlands. Sixteen studies were conducted in other countries.

Twenty-one EHR evaluation purposes were extracted from the retrieved articles. They were categorized into four groups including, technology, human, organization, and system outcomes (Table 2). "System acceptance" was the most frequent purpose (more than one-third of studies). "Measurement of users' satisfaction" was ranked as the second most frequent purpose (19.3\% of studies).

Most EHR evaluations were conducted at hospitals $(66 \%, \mathrm{n}=41)$ and primary care clinics $(16 \%, n=10)$. Eighteen percent of evaluations were conducted in other healthcare contexts, including medical centers, physician offices, health and social service organizations, community health centers, longterm residential care facilities, usability laboratories, and social services organizations. In three studies, EHR evaluation was performed in professional associations (such as the association of physicians).

The EHR evaluation scale was divided into three groups: Small, medium, and large (Table 2). The small scale encompassed EHR evaluations that were performed in one to five health-care organizations $(64.5 \%, \mathrm{n}=40)$. The medium scale included EHR evaluations that were conducted in a geographic region, health-care centers affiliated with a health information system or university, and associations (e.g., association of physicians) $(22.5 \%, n=14)$. The large evaluation scale included EHR evaluations that were performed at the national level $(13 \%, n=8)$.

EHR evaluation was performed in 56\% $(n=35)$ of the studies with a single group of participants. Physicians and nurses $(n=32)$ were the most frequent single group of participants. In $39 \%$ of the studies $(n=24)$, multiple groups of participants were involved for EHR evaluation. Similarly, physicians and nurses played an important role in all of these studies. In $5 \%(n=3)$ of the articles, participants were generally reported as users. Participants with a frequency of $<5$ $(n<5)$ were considered as clinical and non-clinical participants in Table 2.

Clinician participants included physical and occupational therapists $(n=3)$, physiotherapists $(n=2)$, pharmacists $(n=2)$, social workers $(n=1)$, laboratory technologists $(n=1)$, paramedical staff $(n=1)$, radiology staff $(n=1)$, medical secretaries $(n=1)$, and medical technicians $(n=1)$.

Non-clinical participants included managers $(n=6)$, IT staff $(n=5)$, medical record staff $(n=1)$, health informatics professionals $(n=1)$, EHR developers $(n=1)$, financial unit staff $(n=1)$, and quality improvement personnel $(n=1)$. Furthermore, physicians with diverse medical specialties, such as dentists and psychiatrists, were generally classified as physicians.

Among the identified studies, seven data collection methods were used. Questionnaire and interview were the most frequently-used data collection methods with prevalence of $89 \%(n=55)$ and $27 \%$ 
$(\mathrm{n}=17)$, respectively. Other data collection methods, including brainstorming, observation, focus group, log file audit, and scenario were only used along with a questionnaire or interview.

\section{Table 2: Characteristics of the identified studies}

\begin{tabular}{|c|c|}
\hline Location & $\begin{array}{l}\text { US }(n=19) \text {, Taiwan }(n=13) \text {, Iran }(n=4) \text {, Canada }(n=4) \text {, UK }(n=3) \text {, } \\
\text { Netherlands }(n=3) \text {, Austria }(n=1) \text {, Haiti }(n=1) \text {, Croatia }(n=1) \text {, Spain } \\
(n=1) \text {, Greek }(n=1) \text {, Finland }(n=1) \text {, Denmark }(n=1) \text {, Saudi Arabia }(n=1) \text {, } \\
\text { Japan }(n=1) \text {, Singapore }(n=1) \text {, Malaysia }(n=1) \text {, Indonesia }(n=1) \text {, South } \\
\text { Korea }(n=1) \text {, South Africa }(n=1) \text {, New Zealand }(n=1) \text {, and Korea }(n=1)\end{array}$ \\
\hline $\begin{array}{l}\text { EHR evaluation } \\
\text { purposes }\end{array}$ & $\begin{array}{l}\text { Technology: System evaluation }(n=3) \text {, system quality }(n=2) \text {, usability } \\
(n=2) \text {, and system capabilities }(n=1) \text {, system success }(n=1) \text {, technical } \\
\text { analysis }(n=1) \text {, functional requirements }(n=1) \text {, system effectiveness } \\
(n=1) \\
\text { Human: System adoption ( }(n=23) \text {, user satisfaction }(n=11) \text {, behavioral } \\
\text { intentions to system use }(n=4) \text {, and users' attitudes }(n=1) \text {, user } \\
\text { perception }(n=1) \text {, users' experiences ( } n=1) \\
\text { Organization: Personal analysis }(n=1) \text {, organizational analysis } \\
(n=1) \text {, work system challenges }(n=1) \text {, system effect on outcome } \\
\text { quality patient care }(n=2) \text {, system-costs and benefits }(n=1) \text {, nurses' } \\
\text { perceptions of the system impact on clinical practice }(n=1)\end{array}$ \\
\hline $\begin{array}{l}\text { Healthcare } \\
\text { context }\end{array}$ & $\begin{array}{l}\text { Single: Inpatient: Hospital }(n=41) \text {, medical center }(n=1) \text {. Outpatient: } \\
\text { Primary care clinic }(n=10) \text {, physician office }(n=2) \text {, health and social } \\
\text { services organizations }(n=1) \text {, school of nursing }(n=1) \text {, community } \\
\text { health centers }(n=1) \text {. Long-term residential care facilities }(n=1) \text {. } \\
\text { Usability laboratory }(n=1) \\
\text { Multiple }(n=2) \text { : Hospital and primary care clinic }(n=1) \text {, hospital and } \\
\text { nursing home }(n=1) \\
\text { Special association: }(n=3) \\
\text { Not mentioned }(n=1)\end{array}$ \\
\hline Evaluation scale & $\begin{array}{l}\text { Small scale }(n=40): 1 \text { organization }(n=28), 2 \text { organizations }(n=3), 3 \\
\text { organizations }(n=4), 4 \text { organizations }(n=2), 5 \text { organizations }(n=3) \\
\text { Medium scale }(n=14) \text { : A certain geographic region }(n=5) \text {, health care } \\
\text { centers affiliated to a health information system or university }(n=6) \text {, the } \\
\text { members of an association }(n=3) \\
\text { Large scale }(n=8) \text { (national) }\end{array}$ \\
\hline Participants & $\begin{array}{l}\text { Single participant }(n=35) \text { : Clinicians: Physicians }(n=18) \text { and nurses } \\
(n=14) \text {. Non-clinical participants: Managers }(n=2) \text {. Patients }(n=1) \\
\text { Multiple participants }(n=24) \text { : Physicians and nurses }(n=7) \text {, physicians } \\
\text { or nurses with other clinicians }(n=8) \text {, physicians or nurses with } \\
\text { non-clinical participants }(n=5) \text {, physicians, nurses, clinicians, and } \\
\text { non-clinical participants }(n=3) \text {, and physicians, nurses, non-clinical } \\
\text { participants, and patient }(n=1) \text {. } \\
\text { Users (in general): }(n=3) \text {. }\end{array}$ \\
\hline $\begin{array}{l}\text { Data collection } \\
\text { methods }\end{array}$ & $\begin{array}{l}\text { Single }(n=49) \text { : Questionnaire }(n=44) \text { and interview }(n=5) \text {. } \\
\text { Mixed }(n=13) \text { : } \\
2 \text { methods: Questionnaire and interview }(n=5) \text {, interview and } \\
\text { observation }(n=2) \text {, questionnaire and scenario-based }(n=1) \\
3 \text { methods: Questionnaire, interview, and observation }(n=2) \\
4 \text { or } 5 \text { methods: Questionnaire, interviews, observation, and focus } \\
\text { group }(n=1) \text {, questionnaire, interviews, brainstorming, and scenario- } \\
\text { based }(n=1) \text {, and questionnaire, interviews, observation, scenario- } \\
\text { based, and log file audit }(n=1)\end{array}$ \\
\hline
\end{tabular}

\section{RF of the evaluation measures and dimensions in technology, human, and organization aspects}

The range of the RF in third-level of hierarchical structure was between $0.2 \%$ and $61 \%$. The "ease of use" evaluation measure had the highest RF. Evaluation measures such as flexibility, mobility, and confusion that had the lowest RF were used just in one study. The most frequent evaluation measures in the identified studies as were following,

- $\quad$ Technology: Ease of use (fi: 0.61), usefulness (fi: 0.52 ), usability (fi: 0.21 ), reliability (fi: 0.21 ), and accuracy (fi: 0.21)

- Human: Satisfaction (fi: 0.29), (behavioral) intention of use (fi: 0.34), and computer knowledge and skills (fi: 0.18)

- Organization: Effects on outcome quality of care (fi: 37.1 ), social context (fi: 0.21), compatibility and fitness with the work process (fi: 0.18$)$, and effects on outcome quality of care (fi: 0.18).

The range of the RF of in second-level of hierarchical structure was between $8.6 \%$ and $91.94 \%$. "System quality" (RF: 91.94), "users' satisfaction" (RF: 56.45), "characteristics of the organization and organizational factors" (RF: 53.23), and "service quality" (RF: 53.23) were the most-frequently evaluated dimensions, respectively. "Environment" dimension was the least-frequently evaluated dimensions in the identified studies. Table 3 shows the RF of evaluation measures in the dimensions related to three aspects including technology, human, and organization. Appendix 2-4 demonstrates the detailed list of evaluation measures, dimensions, aspects. Tables 3 and 4 shows the RF of evaluation measures and dimensions and the maximum coverage rate of the evaluation measures in evaluation dimensions and aspects, respectively.

\section{Coverage rate of evaluation measures in identified studies (frameworks)}

Almost in all identified studies evaluation measures related to the technology aspect were appropriately, moderately, or poorly covered. However, evaluation measures related to human and organization aspects were covered in $68 \%, 84 \%$ of the identified studies, respectively. About $53 \%$ of the identified studies covered evaluation measures related to three aspects. However, none of them covered evaluation measures of all three aspects appropriately. Evaluations measures related to dimensions of "characteristics of the organization and organizational factors," "Users' satisfaction," and "System quality" had the highest appropriately evaluation measure coverage rate (Table 5).

Three-level hierarchical structure contains 12 dimensions which cover three aspects including technology, human, and organization. Identified studies cover at least one and at most nine dimensions.

Two studies [19], [20], four studies [21], [22], [23], [24], and five studies [2], [25], [26], [27], [28] covered 9,8 , and 7 dimensions, respectively.

Nine studies [3], [4], [9], [20], [21], [29], [30], [31], [32] appropriately covered evaluation measures in the technology aspect. In human and organization aspects, the coverage rate of evaluation measures in six [23], [24], [33], [34], [35], [36] and four studies [9], [20], [37], [38] was better than other studies, respectively. Almost $40 \%$ of evaluations measures related to the human and organization aspects were covered by these studies. Table 6 [39], [40], [41], [42], [43], [44], [45], [46], [47], [48], [49], [50], [51], [52], [53], [54], [55], [56], [57], [58], [59], [60], [61], [62], [63], [64], [65], [66], [67], [68], [69], [70], [71], [72] shows the coverage of evaluation measures for identified studies. In this table dimensions related to technology, human, and organization aspects were reported as following abbreviation, T1-T3 and TT 
for technology aspect, $\mathrm{H} 1-\mathrm{H} 5$ and $\mathrm{TH}$ for human aspect, and 01-04 and TO for organization aspect. In this table, the coverage rate of evaluation measures was represented by color cells. The white, light gray, dark gray, and balk cells show no-coverage, low, moderate, and appropriate coverage, respectively.

Figure 3 shows the coverage rate of evaluation measures in three aspects of technology, human, and organization for the identified studies.

Table 3: The maximum coverage rate of the evaluation measures in evaluation dimensions and aspects

\begin{tabular}{ll}
\hline $\begin{array}{l}\text { Evaluation aspects (The } \\
\text { maximum coverage rate) }\end{array}$ & Evaluation dimensions (The maximum coverage rate) \\
\hline Technology (4.62) & System quality (2.45) \\
& Information quality (1.44) \\
& Service quality $(0.73)$ \\
Human (2.06) & Users' satisfaction $(0.65)$ \\
& System use $(0.68)$ \\
& Users characteristics and personality $(0.31)$ \\
& Computer knowledge and self-efficacy $(0.16)$ \\
& Positive or negative feeling about EHR $(0.26)$ \\
Organization (1.61) & Characteristics of organization and organizational factors \\
& $(0.98)$ \\
& Net benefit and EHR effects on workflow and organization \\
& $(0.37)$ \\
& EHR effects on outcome quality of care $(0.18)$ \\
& Environment (0.08)
\end{tabular}

In Figure 3, the horizontal $(X)$ axis shows the coverage rate of the technology aspect and the vertical $(Y)$ axis shows the coverage rate of the organization aspect. Identified studies are plotted as circles of different color and white triangle. The color of each circle in $X Y$ coordinates represents the coverage rate of the corresponding identified studies in the human aspect. The white, gray, and balk circles show low, moderate, and appropriate coverage, respectively. White triangle represents no-coverage. The number of each circle was assigned based on the number list of identified studies in Table 6.

There are two thresholds of $25 \%$ and $50 \%$ on both the horizontal and vertical axes. These thresholds determine the coverage cutoff points of low, moderate, and appropriate coverage in each axis, which creates a total of nine zones (these zones are represented by $Z$ followed by a number between 1 and 9 ). The minimum and maximum values on the technology (horizontal) axis are zero and $60 \%$, respectively. There is a rising trend of coverage rate in the technology aspect from left to right. Based on the represented coverage rates in Figure 1, it is expected to observe low coverage in

Table 4: The relative frequency of evaluation measures and dimensions

\begin{tabular}{|c|c|c|}
\hline $\begin{array}{l}\text { Evaluation } \\
\text { aspects }\end{array}$ & Evaluation dimensions (relative frequency \%) & Evaluation measures (relative frequency \%) \\
\hline \multirow[t]{3}{*}{ Technology } & System quality (91.9) & $\begin{array}{l}\text { Ease of Use }(0.61) \text {, usefulness }(0.52) \text {, usability }(0.21) \text {, reliability }(0.21) \text {, response time }(0.13) \text {, accessibility }(0.10) \text {, sufficient } \\
\text { resources }(0.19) \text {, privacy and security }(0.11) \text {, availability }(0.08) \text {, system function }(0.06) \text {, system interoperability and } \\
\text { integration }(0.15) \text {, complexity }(0.03) \text {, flexibility }(0.02) \text {, mobility }(0.02) \text {, confusion }(0.02)\end{array}$ \\
\hline & Information quality (41.9) & $\begin{array}{l}\text { Accuracy }(0.21) \text {, Completeness }(0.18) \text {, Timeliness }(0.13) \text {, Format }(0.13) \text {, Sufficiently }(0.11) \text {, ease of use }(0.10) \text {, availability } \\
(0.06) \text {, up-to-date }(0.06) \text {, accessibility }(0.05) \text {, legibility }(0.05) \text {, reliability }(0.05) \text {, relevance }(0.05) \text {, consistency }(0.03) \text {, } \\
\text { compatibility }(0.05) \text {, clear }(0.03) \text {, currency }(0.03) \text {, content }(0.02) \text {, secure and confidential }(0.02) \text {, right data }(0.02) \text {, right } \\
\text { level of detail }(0.02) \text {, Locatability }(0.02) \text {, meaning }(0.02) \text {, authorization }(0.02)\end{array}$ \\
\hline & Service quality (53.2) & $\begin{array}{l}\text { Training }(0.16) \text {, responsiveness }(0.10) \text {, assurance }(0.13) \text {, empathy }(0.08) \text {, it staffs availability and providing it support } \\
(0.10) \text {, pay attention to user needs }(0.05) \text {, system guideline or users' manual }(0.03) \text {, production timeliness }(0.02) \text {, } \\
\text { assistance }(0.02) \text {, follow-up service }(0.02) \text {, reliability }(0.02) \text {, is performance }(0.02)\end{array}$ \\
\hline \multirow[t]{5}{*}{ Human } & Users' Satisfaction (56.5) & $\begin{array}{l}\text { Satisfaction (0.29), attitude toward system }(0.18) \text {, system acceptance }(0.11) \text {, users' expectations }(0.05) \text {, personality traits } \\
(0.02)\end{array}$ \\
\hline & System use (48.4) & $\begin{array}{l}\text { (Behavioral) Intention of use }(0.34) \text {, system use }(0.19) \text {, frequency of use }(0.05) \text {, intensity of use }(0.02) \text {, level of use }(0.02) \text {, } \\
\text { reason to use }(0.02) \text {, observability }(0.02) \text {, information about change }(0.02) \text {, trialability }(0.02)\end{array}$ \\
\hline & Computer knowledge and Self-efficacy (14.5) & Computer knowledge and skills $(0.18)$, self-efficacy $(0.13)$ \\
\hline & Users characteristics and personality (27.4) & General characteristics $(0.13)$, personal identity $(0.02)$, innovativeness $(0.02)$ \\
\hline & Positive or negative feeling about EHR (19.4) & $\begin{array}{l}\text { Concerns for EHR }(0.10) \text {, perceived threat }(0.03) \text {, perceived risk }(0.02) \text {, instructional trust }(0.02) \text {, optimism }(0.02) \text {, } \\
\text { discomfort }(0.02) \text {, anxiety }(0.02) \text {, insecurity }(0.02) \text {, inequity }(0.02) \text {, resistance to change }(0.02)\end{array}$ \\
\hline \multirow[t]{4}{*}{ Organization } & $\begin{array}{l}\text { Characteristics of organization and } \\
\text { Organizational factors }(53.2)\end{array}$ & $\begin{array}{l}\text { Social context }(0.21) \text {, compatibility and fitness with the work process }(0.18) \text {, management support }(0.08) \text {, physician } \\
\text { involvement }(0.03) \text {, organization characteristics }(0.05) \text {, physician autonomy }(0.03) \text {, communication }(0.03) \text {, organization } \\
\text { structure }(0.03) \text {, coherence }(0.02) \text {, cognitive participation }(0.02) \text {, collective action }(0.02) \text {, reflexive monitoring }(0.02) \text {, } \\
\text { monitoring and feedback }(0.02) \text {, leadership }(0.02) \text {, physical proximity }(0.02) \text {, competition }(0.02) \text {, employee understanding } \\
\text { and support of implementation }(0.03) \text {, organizational support for implementation }(0.02) \text {, innovative culture in hospital } \\
(0.02) \text {, open culture in hospital }(0.02) \text {, situational normality }(0.02) \text {, strategy }(0.02) \text {, supporting best practices }(0.02) \text {, } \\
\text { supportive norms }(0.02) \text {, task equivocality }(0.02) \text {, task interdependence }(0.02) \text {, caseload }(0.02) \text {, voluntary turnover }(0.02)\end{array}$ \\
\hline & Effects on workflow and organization (37.1) & Equal to dimension \\
\hline & Effects on outcome quality of care (17.7) & Equal to dimension \\
\hline & Environment (8.1) & Equal to dimension \\
\hline
\end{tabular}
HER: Electronic health records.

(1) on worklow and organization (37.1)

Table 5: The coverage rate in EHR evaluation dimensions

\begin{tabular}{|c|c|c|c|c|c|}
\hline \multirow[t]{3}{*}{ Aspects } & \multirow[t]{3}{*}{ Dimensions } & \multicolumn{4}{|c|}{ Coverage $(\mathrm{n}=62)$} \\
\hline & & No-coverage & Low & Moderate & Appropriate \\
\hline & & $\mathrm{n}(\%)$ & $\mathrm{n}(\%)$ & $\mathrm{n}(\%)$ & $\mathrm{n}(\%)$ \\
\hline \multirow[t]{3}{*}{ Technology } & System quality & $5(8.1)$ & $10(16.1)$ & $28(45.2)$ & $19(30.6)$ \\
\hline & Information quality & $36(58.1)$ & $9(14.5)$ & $10(16.1)$ & $7(11.3)$ \\
\hline & Service quality & $29(46.8)$ & $12(19.4)$ & $8(12.9)$ & $13(21)$ \\
\hline \multirow[t]{5}{*}{ Human } & Users' satisfaction & 27 (43.5) & $16(25.8)$ & $16(25.8)$ & $3(4.8)$ \\
\hline & System use & $32(51.6)$ & $3(4.8)$ & $6(9.7)$ & $21(33.9)$ \\
\hline & Users characteristics and personality & $53(85.5)$ & $1(1.6)$ & $0(0)$ & $8(12.9)$ \\
\hline & Computer knowledge and self-efficacy & 45 (72.6) & $0(0)$ & $6(9.7)$ & $11(17.7)$ \\
\hline & Positive or negative feeling about EHR & $50(80.7)$ & $6(9.7)$ & $6(9.7)$ & $0(0)$ \\
\hline \multirow[t]{4}{*}{ Organization } & Characteristics of organization and organizational factors & $29(46.8)$ & $28(45.2)$ & $5(8.1)$ & $0(0)$ \\
\hline & Net benefit and EHR effects on workflow and organization & 39 (62.9) & $0(0)$ & $0(0)$ & $23(37.1)$ \\
\hline & EHR effects on outcome quality of care & $51(82.3)$ & $0(0)$ & $0(0)$ & $11(17.17)$ \\
\hline & Environment & 57 (91.9) & $0(0)$ & $0(0)$ & $5(8.1)$ \\
\hline
\end{tabular}


Table 6: The coverage rate of evaluation measures in dimensions and aspects for the identified studies

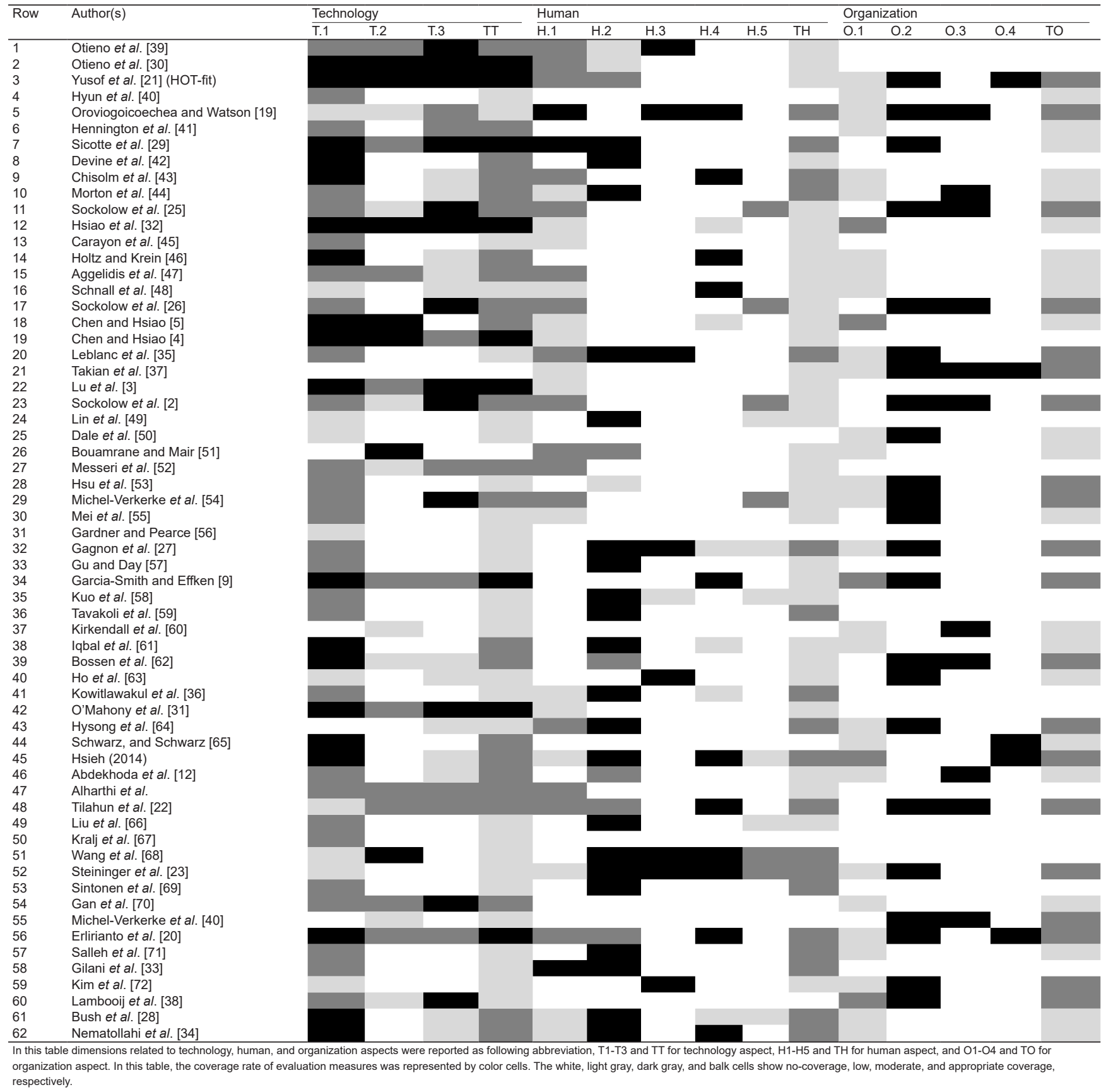

$\mathrm{Z1/Z4}$ and Z7, moderate coverage in Z2/Z5 and Z8, and appropriate coverage in Z3/Z6 and Z9. The circles on the technology (horizontal) axis also represent the noncoverage of a study in the organization aspect.

The minimum and maximum value of the organization (vertical) dimension was zero and $47 \%$, respectively. There is a rising trend in the coverage rate from bottom to top in the organization dimension. It is expected to observe low coverage in $Z 7 / Z 8$ and Z9, moderate coverage in Z4/Z5 and Z6, and appropriate coverage in Z1/Z2 and Z3. The circles on the organization (vertical) axis also represent the noncoverage of a study in the technology aspect.

Z3 shows appropriate coverage rate of identified studies based on the two aspects of technology and organization. If the objective of a particular research is to explore the appropriate identified studies in the technology and organization aspects, Z3 is deemed to find the most suitable studies. The identified studies had a low coverage rate in the organization and technology aspects, and a moderate coverage rate in $Z 7$ and $Z 5$, respectively.

The coverage rate of evaluation measures for different studies is a combination of low, moderate, and appropriate coverage in both technology and organization aspects in Z1, Z2, Z4, Z6, and Z8. Z4, for example, shows studies with low and moderate coverage in the technology and organization aspects, respectively. Z8, on the other hand, illustrates studies with moderate and low coverage in the technology and organization aspects, respectively. 


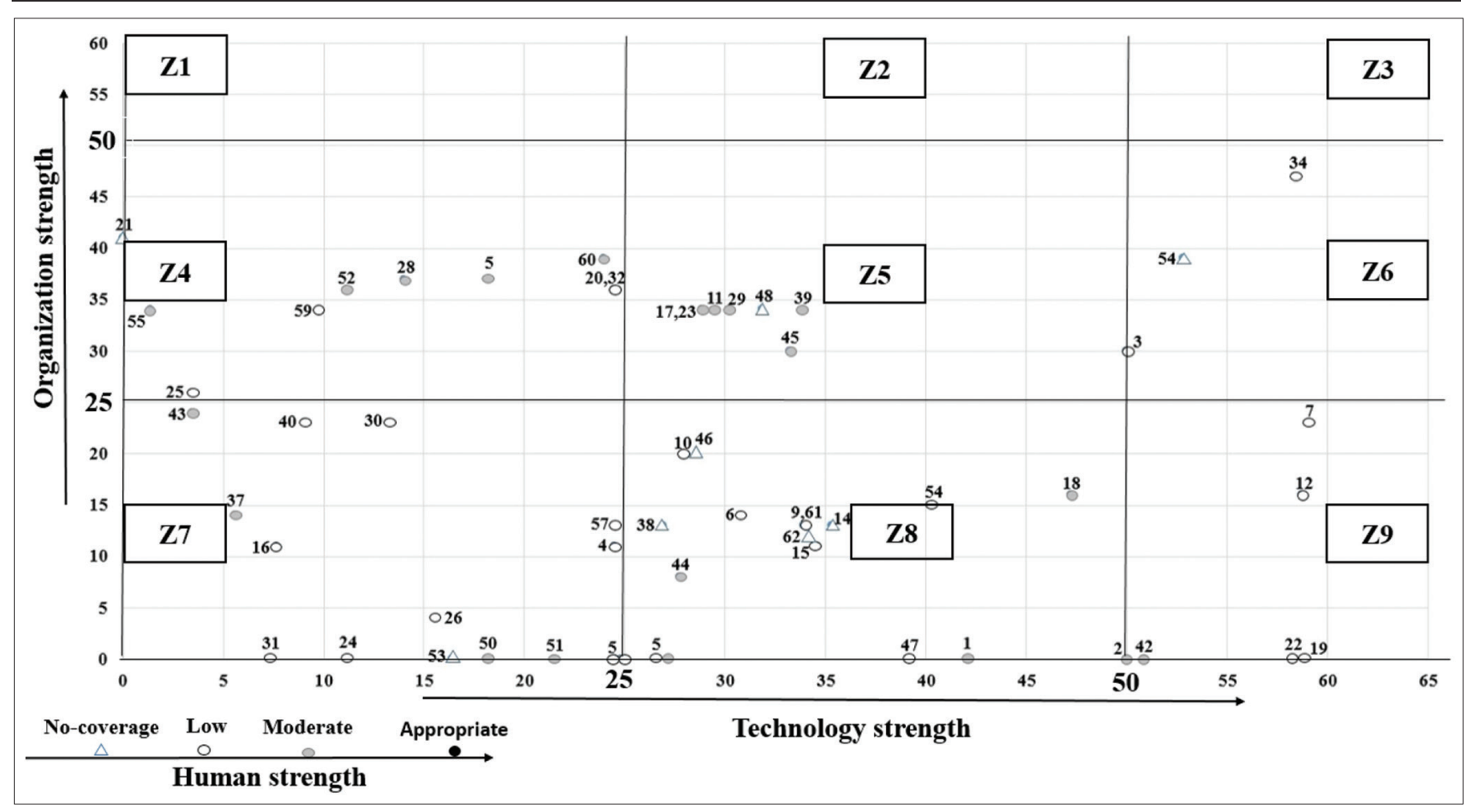

Figure 3: The coverage rate of evaluation measures based on the technology and organization aspects in identified studies

In Figure 4, the horizontal $(X)$ axis shows the coverage rate of the technology aspect and the vertical $(\mathrm{Y})$ axis shows the coverage rate of the human aspect. The color of circles represents the coverage rate of the organization aspect. In Figure 5, the horizontal (X) axis shows the coverage rate of the human aspect and the vertical $(Y)$ axis shows the coverage rate of the organization aspect. The color of circles represents the coverage rate of the technology aspect. The cutoff thresholds depicted in Figures 4 and 5 can be described as the ones in Figure 3. In Figure 4, for example, Z1, $Z 2$, and $Z 3$ show the most appropriate identified studies in the organization aspect. Z7, in Figure 5, includes those studies which possess low coverage rates in both human and organization aspects.

The study by Oroviogoicoechea and Watson [19] is one of the identified studies. The coverage rate of evaluation measures aspects of technology, human, and organization was $18.2 \% 38 \%$, and $37 \%$, respectively. As shown in Figure 6, this study located in Z4. Hence, the study covered technology and organization aspects poorly and moderately. Gray circle represents moderately the coverage rate of the human aspect.

\section{Discussion}

There is no study for determining coverage rate of evaluation measures in the EHR evaluation frameworks presented in the current body of literature.
In this study, a comprehensive literature review was performed to identify current EHR evaluation frameworks and extract evaluation measures. Based on our review and frequency analysis of evaluation measures, a model for determining the coverage rate of evaluation measures in EHR evaluation frameworks was suggested. The most significant findings of the present study are discussed in the following paragraphs.

The findings of the study revealed that $53 \%$ $(n=33)$ of studies covered all three evaluation aspects. The rest of the studies only included one or two aspects. Moreover, the findings of our study demonstrate that the coverage rate of evaluation measures differed with respect to various studies. Although some studies covered one aspect or dimension perfectly, they might not cover other aspects or dimensions. In the best case, $67 \%(n=8)$ to $75 \%(n=9)$ of dimensions are covered by a single study. None of the studies covered all evaluation dimensions in all three aspects of technology, human, and organization. Shaw [73] also observes this finding and points out that there is no comprehensive evaluation framework which covers all evaluation dimensions. For example, the framework presented by Otieno et al. includes evaluation measures of technology and human aspects, but does not cover evaluation measures of the organization aspect [30]. Likewise, in the studies by Garcia-Smith and Effken [9], Lambooij et al. [38], and Takian et al. [37], evaluation measures of the organization aspect were moderately covered, but evaluation measures related to the human aspect were very weak.

Yosef et al. highlight the fact that evaluation measures are not complete by themselves, and rather, 


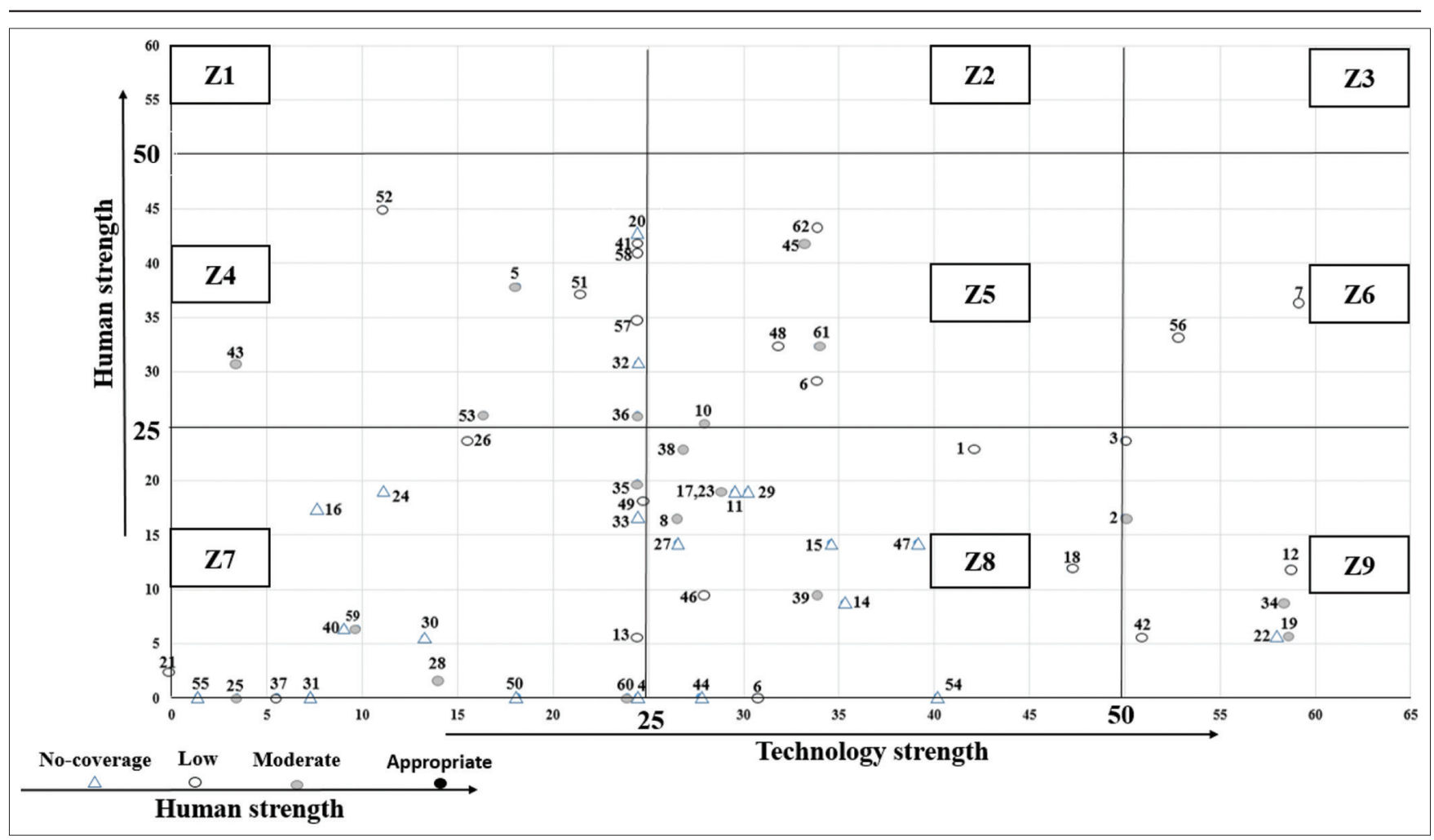

Figure 4: The coverage rate of evaluation measures based on the technology and human aspects in identified studies

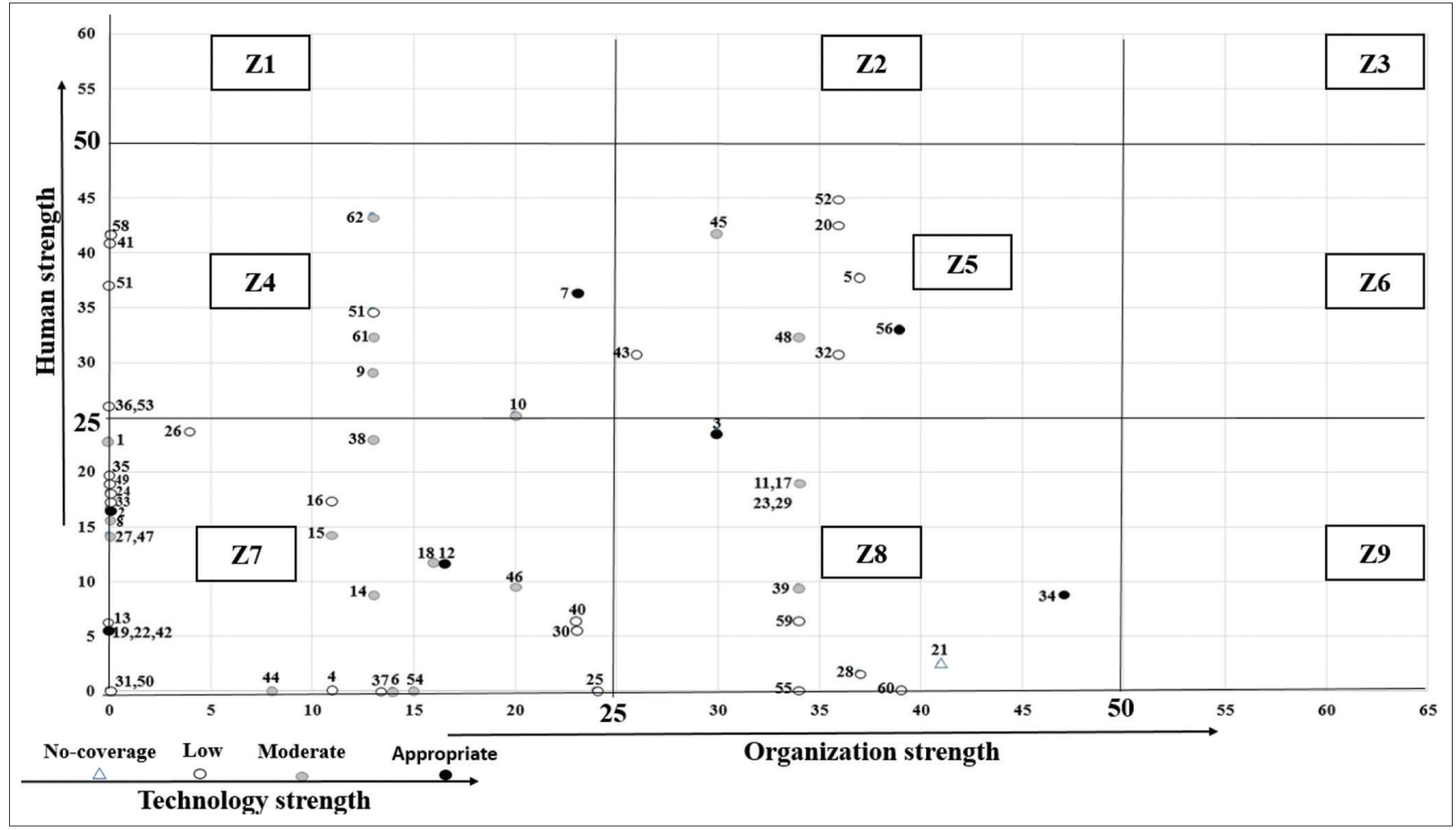

Figure 5: The coverage rate of evaluation measures based on the organization and human aspects in identified studies

they complement each other [14] .The findings of the present study also confirm this fact. Evaluation frameworks can potentially cover the shortcomings of other frameworks. This underscores the importance of a model for determining the coverage rate of evaluation measures in the EHR evaluation frameworks. Results of the present study enable users to observe the coverage rate of different evaluation measures in identified frameworks in the three aspects of technology, human, and organization. The users can understand the strengths and limitations of EHR evaluation frameworks. Furthermore, they can explore the focuses 


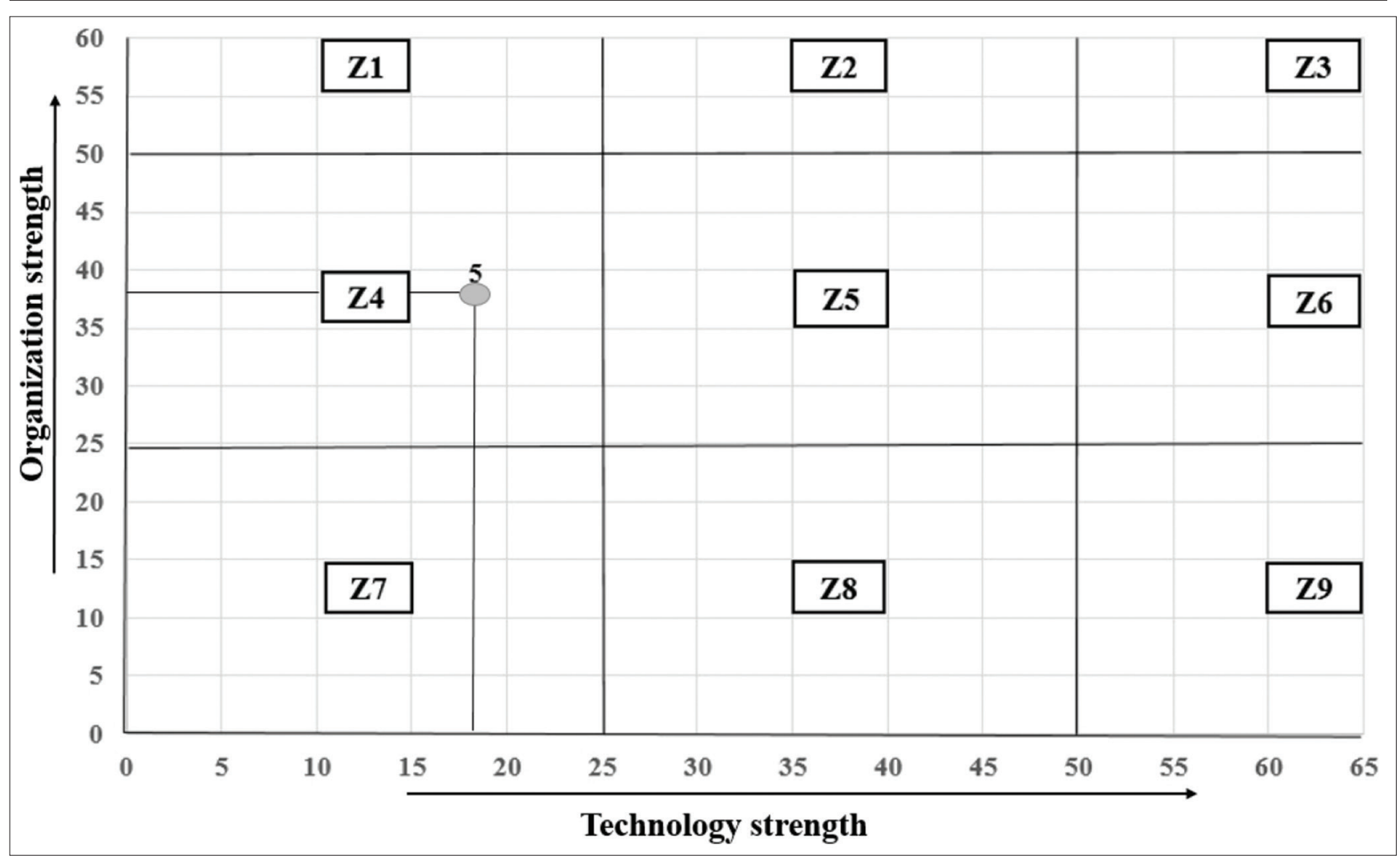

Figure 6: The coverage rate of evaluation measures aspects of technology, organization, and human in the study by Oroviogoicoechea and Watson

of identified frameworks. For example, we elaborate on three frameworks with different characteristics in terms of coverage rate in the three aspects above.

Hsiao et al.'s framework [32] appropriately covers the technology aspect and weakly covers the dimensions of organization and human aspects. CISSM [9] like Hsiao et al.'s framework appropriately covers the technology aspect. In addition, this framework moderately covers organization. Unlike CISSM, Steiniger et al.'s framework [23] covers the human aspect moderately, but weakly covers the evaluation measures of the technology aspect. Therefore, the users can compare the coverage rate of evaluation measures in the EHR evaluation frameworks and choose the most suitable framework based on the focus of their study.

As well, our results show that the coverage rate of evaluation measures differs in various dimensions of the three aspects. Hsiao et al.'s framework [32] appropriately covers the three dimensions of technology aspect. In the technology aspect, CISSM [9] mostly focuses on the system quality dimension and moderately covers the two dimensions of service quality and information quality. CISSM and Takian et al.'s framework [37] both moderately covers the evaluation measures in the organization aspect. However, CISSM focuses on dimensions of "characteristics of the organization and organizational factors" and "effects on workflow and organization" and does not cover the two dimensions of "effects on outcome quality of care" and environment. Takian et al.'s framework puts its emphasis on the dimension of "effects on workflow and organization," "effects on outcome quality of care", and "environment."

In most of the identified studies, researchers developed an EHR evaluation framework. This is mostly due to the gaps and shortcomings of the current framework for the context of use or purpose, which has led to an original framework. For example, ISSM does not cover organizational factors. Therefore, Yusof et al. developed the HOT-fit framework based on the ISSM and the IT-Organization fit frameworks and added those dimensions to the ISSM. Similarly, Garcia et al. realized that satisfaction indicators in the ISSM did not show why users were satisfied or dissatisfied with an information system and, thus, could not measure the success of an information system. They used the TAM2 and UTAUT, which included user satisfaction factors for the CISSM development [9]. Furthermore, Chen et al. found out one limitation of the TAM to be the lack of influence of external variables and barriers to technology acceptance. They proposed a modified TAM derived from TAM and HOT-fit to explore factors affecting physicians' acceptance of a HIS [5].

Most of the original EHR evaluation frameworks were using a common basis. The UTAUT, TAM, TIB, 
and theory of planned behavior (TPB) are based on user-acceptance theory. The ISSM was also used in approximately twenty percent of the identified articles. For example, hybrid evaluation frameworks from ISSM and TAM were used in some studies [3], [5], [29], [42]. Kim et al. [72] and lqbal et al. [61] developed original frameworks with UTAUT and TAM. Hybrid evaluation frameworks based on ISSM were used in a number of studies [9], [21], [22], [29], [30], [39], [47], [52], [62], [71], [74]. TAM with others framework was implemented in some studies [5], [27], [40], [44], [49], [58], [66], [69]. In a number of studies frameworks based on UTAUT were used [28], [31], [43], [61], [72].

We found out that the primary purpose of several frameworks was not EHR evaluation. Rather, the authors made several modifications and enhancements to turn them into a usable EHR evaluation framework. For example, the TPB was suggested in 1991 by Ajzen and Icek. TPB provided an effective conceptual framework for dealing with the complexities of human social behavior [75]. Hsieh modified TPB to account for the evaluation of physicians' acceptance of electronic medical records exchange [24]. Demerouti et al. developed the Job Demands Resource Model (JDRM) in 2001. JDRM proved that job demands require sustained physical or mental effort. Hysong et al. combined JDRM and UTAUT for the user acceptance assessment [64]. Burt provided social contagion theory (SCT) in 1987. SCT describes how ideas or opinions spread in a social network [76], [77]. Gan et al. created a hybrid framework with SCT and TTF for evaluation of EHR adoption [70].

One of the limitations of this study was that it was based only on articles written in English. Thus, it may not have covered those frameworks that might have been published in non-English-language studies. In addition, in the current study, dimensions of EHR evaluation frameworks were not reported and classified. This can be conducted in future studies.

In future studied an expert team can review identified evaluation measures in the technology, human, and organization aspects and provide a comprehensive EHR evaluation framework.

\section{Conclusion}

In this study, we systematically reviewed all literature presenting any type of EHR evaluation framework and analyzed and discussed their aspects and features. We believe that the findings of this study can help researchers to review and adopt the EHR evaluation frameworks for their own particular field of usage.

\section{Acknowledgment}

The current study was a part of the doctorate thesis (research plan code: 951350) and supported by Mashhad University of Medical Sciences.

\section{References}

1. Nykanen P, Brender J, Talmon J, de Keizer N, Rigby M, BeuscartZephir MC, et al. Guideline for good evaluation practice in health informatics (GEP-HI). Int J Med Inform. 2011;80(12):815-27. https://doi.org/10.1016/j.jimedinf.2011.08.004 PMid:21920809

2. Sockolow PS, Crawford PR, Lehmann HP. Health services research evaluation principles. Broadening a general framework for evaluating health information technology. Methods Inf Med. 2012;51(2):122-30. https://doi.org/10.3414/me10-01-0066 PMid:22311125

3. Lu CH, Hsiao JL, Chen RF. Factors determining nurse acceptance of hospital information systems. Comput Inform Nurs. 2012;30(5):257-64.

PMid:22228251

4. Chen RF, Hsiao JL. An empirical study of physicians' acceptance of hospital information systems in Taiwan. Telemed J E Health. 2012;18(2):120-5.

PMid:22283362

5. Chen RF, Hsiao JL. An investigation on physicians' acceptance of hospital information systems: A case study. Int J Med Inform. 2012;81(12):810-20

PMid:22652011

6. Holden RJ, Karsh BT. The technology acceptance model: Its past and its future in health care. J Biomed Inf. 2010;43(1):15972. https://doi.org/10.1016/j.jbi.2009.07.002 PMid:19615467

7. Davis FD, Bagozzi RP, Warshaw PR. User acceptance of computer technology: A comparison of two theoretical models. Manage Sci. 1989;35(8):982-1003. https://doi.org/10.1287/ mnsc.35.8.982

8. Venkatesh V, Morris MG, Davis GB, Davis FD. User acceptance of information technology: Toward a unified view. MIS Quart. 2003;27(3):425-78. https://doi.org/10.2307/30036540

9. Garcia-Smith D, Effken JA. Development and initial evaluation of the clinical information systems success model (CISSM). Int J Med Inform. 2013;82(6):539-52. https://doi.org/10.1016/j. ijmedinf.2013.01.011

PMid:23497819

10. Nguyen L, Bellucci E, Nguyen LT. Electronic health records implementation: An evaluation of information system impact and contingency factors. Int J Med Inform. 2014;83(11):779-96. https://doi.org/10.1016/j.jjmedinf.2014.06.011 PMid:25085286

11. DeLone WH, McLean ER. The Delone and McLean model of information systems success. JMIS. 2003;19(4):9-30.

12. Abdekhoda M, Ahmadi M, Gohari M, Noruzi A. The effects of organizational contextual factors on physicians' attitude toward adoption of electronic medical records. J Biomed Inf. 2015;53:174-9. https://doi.org/10.1016/j.jbi.2014.10.008 
PMid:25445481

13. Currie LM. Evaluation frameworks for nursing informatics. Int $J$ Med Inform. 2005;74(11-12):908-16.

PMid:16099711

14. Yusof MM, Papazafeiropoulou A, Paul RJ, Stergioulas LK. Investigating evaluation frameworks for health information systems. Int J Med Inform. 2008;77(6):377-85. https://doi. org/10.1016/j.ijmedinf.2007.08.004

PMid:17904898

15. Ahmadian L, Nejad SS, Khajouei R. Evaluation methods used on health information systems (HISs) in Iran and the effects of HISs on Iranian healthcare: A systematic review. Int J Med Inform. 2015;84(6):444-53. https://doi.org/10.1016/j. ijmedinf.2015.02.002

PMid:25746766

16. Ammenwerth $\mathrm{E}$, de Keizer N. An inventory of evaluation studies of information technology in health care: Trends in evaluation research 1982-2002. Stud Health Technol Inform. 2004;107(2):1289-94. https://doi.org/10.1055/s-0038-1633922 PMid:15361022

17. Sadoughi F, Kimiafar K, Ahmadi M, Shakeri MT. Determining of factors influencing the success and failure of hospital information system and their evaluation methods: A systematic review. Iran Red Crescent Med J. 2013;15(12):e11716. https:// doi.org/10.5812/ircmj.11716 PMid:24693386

18. Hayrinen K, Saranto K, Nykanen P. Definition, structure, content, use and impacts of electronic health records: A review of the research literature. Int J Med Inform. 2008;77(5):291-304. https://doi.org/10.1016/j.ijmedinf.2007.09.001

PMid:17951106

19. Oroviogoicoechea C, Watson R. A quantitative analysis of the impact of a computerised information system on nurses' clinical practice using a realistic evaluation framework. Int $\mathrm{J}$ Med Inform. 2009;78(12):839-49. https://doi.org/10.1016/j. ijmedinf.2009.08.008

PMid:19767235

20. Erlirianto LM, Ali AH, Herdiyanti A. The implementation of the human, organization, and technology-fit (HOT-fit) framework to evaluate the electronic medical record (EMR) system in a hospital. Proc Comput Sci. 2015;72:580-7. https://doi. org/10.1016/j.procs.2015.12.166

21. Yusof MM, Kuljis J, Papazafeiropoulou A, Stergioulas LK. An evaluation framework for health information systems: Human, organization and technology-fit factors (HOT-fit). Int J Med Inform. 2008;77(6):386-98. https://doi.org/10.1016/j. ijmedinf.2007.08.011

PMid:17964851

22. Tilahun B, Fritz F. Modeling antecedents of electronic medical record system implementation success in low-resource setting hospitals. BMC Med Inform Decis Mak. 2015;15:61. https://doi. org/10.1186/s12911-015-0192-0

23. Steininger K, Stiglbauer B. EHR acceptance among Austrian resident doctors. Health Policy Technol. 2015;4(2):121-30. https://doi.org/10.1016/j.hlpt.2015.02.003

24. Hsieh PJ. Physicians' acceptance of electronic medical records exchange: An extension of the decomposed TPB model with institutional trust and perceived risk. Int $\mathrm{J}$ Med Inform. 2015;84(1):1-14. https://doi.org/10.1016/j.ijmedinf.2014.08.008 PMid:25242228

25. Sockolow PS, Weiner JP, Bowles KH, Lehmann HP. A new instrument for measuring clinician satisfaction with electronic health records. Comput Inform Nurs. 2011;29(10):574-85 https://doi.org/10.1097/ncn.0b013e31821a1568

PMid:21543972
26. Sockolow PS, Bowles KH, Lehmann HP, Abbott PA, Weiner JP. Community-based, interdisciplinary geriatric care team satisfaction with an electronic health record: A multimethod study. Comput Inform Nurs. 2012;30(6):300-11. https://doi. org/10.1097/ncn.0b013e31823eb561

PMid:22411417

27. Gagnon MP, Ghandour EK, Talla PK, Simonyan D, Godin G, Labrecque M, et al. Electronic health record acceptance by physicians: Testing an integrated theoretical model. J Biomed Inform. 2014;48:17-27.

PMid:24184678

28. Bush RA, Kuelbs C, Ryu J, Jiang W, Chiang G. Structured data entry in the electronic medical record: Perspectives of pediatric specialty physicians and surgeons. J Med Syst. 2017;41(5):75 https://doi.org/10.1007/s10916-017-0716-5

PMid:28324321

29. Sicotte C, Pare G, Bini KK, Moreault MP, Laverdure G. Virtua organization of hospital medical imaging: A user satisfaction survey. J Digit Imaging. 2010;23(6):689-700. https://doi. org/10.1007/s10278-009-9220-x

PMid:19588196

30. Otieno GO, Hinako T, Motohiro A, Daisuke K, Keiko N Measuring effectiveness of electronic medical records systems: Towards building a composite index for benchmarking hospitals. Int J Med Inform. 2008;77(10):657-69. https://doi.org/10.1016/j. ijmedinf.2008.01.002

PMid:18313352

31. O'Mahony D, Wright G, Yogeswaran P, Govere F. Knowledge and attitudes of nurses in community health centres about electronic medical records. Curationis. 2014;37(1):1150. https:// doi.org/10.4102/curationis.v37i1.1150

PMid:24832678

32. Hsiao JL, Chang HC, Chen RF. A study of factors affecting acceptance of hospital information systems: A nursing perspective. J Nurs Res. 2011;19(2):150-60. https://doi. org/10.1097/jnr.0b013e31821cbb25

PMid:21586992

33. Gilani MS, Iranmanesh M, Nikbin D, Zailani S. EMR continuance usage intention of healthcare professionals. Inform Health Soc Care. 2017;42(2):153-65. https://doi.org/10.3109/17538157.20 16.1160245

PMid:27100821

34. Nematollahi M, Moosavi A, Lazem M, Aslani N, Kafashi M, Garavand A. Factors affecting in adoption and use of electronic medical record based on unified theory of acceptance and use of technology in Iran. Shiraz E Med J. 2017;18(9):e57582. https://doi.org/10.5812/semj.57582

35. Leblanc G, Gagnon MP, Sanderson D. Determinants of primary care nurses' intention to adopt an electronic health record in their clinical practice. Comput Inform Nurs. 2012;30(9):496-502. https://doi.org/10.1097/nxn.0b013e318257db17

PMid:22592453

36. Kowitlawakul Y, Chan SW, Pulcini J, Wang W. Factors influencing nursing students' acceptance of electronic health records for nursing education (EHRNE) software program. Nurse Educ Today. 2015;35(1):189-94. https://doi.org/10.1016/j. nedt.2014.05.010

PMid:24947068

37. Takian A, Sheikh A, Barber N. We are bitter, but we are better off: Case study of the implementation of an electronic health record system into a mental health hospital in England. BMC Health Serv Res. 2012;12:484. https://doi.org/10.1186/1472-6963-12-484 PMid:23272770

38. Lambooij MS, Drewes HW, Koster F. Use of electronic medical records and quality of patient data: Different reaction patterns 
of doctors and nurses to the hospital organization. BMC Med Inform Decis Mak. 2017;17(1):1-11. https://doi.org/10.1186/ s12911-017-0412-x

39. Otieno OG, Toyama $\mathrm{H}$, Asonuma $\mathrm{M}$, Kanai-Pak $\mathrm{M}$, Naitoh K. Nurses' views on the use, quality and user satisfaction with electronic medical records: Questionnaire development. J Adv Nurs. 2007;60(2):209-19. https://doi. org/10.1111/j.1365-2648.2007.04384.x

\section{PMid: 17877568}

40. Hyun S, Johnson SB, Stetson PD, Bakken S. Development and evaluation of nursing user interface screens using multiple methods. J Biomed Inform. 2009;42(6):1004-12. https://doi. org/10.1016/j.jbi.2009.05.005

PMid:19460464

41. Hennington A, Janz B, Amis J, Nichols E. Understanding the multidimensionality of information systems use: A study of nurses' use of a mandated electronic medical record system. Commun Assoc Inf Syst. 2009;25(1):243-62. https://doi. org/10.17705/1cais. 02525

42. Devine EB, Patel R, Dixon DR, Sullivan SD. Assessing attitudes toward electronic prescribing adoption in primary care: A survey of prescribers and staff. Inform Prim Care. 2010;18(3):177-87. https://doi.org/10.14236/jhi.v18i3.770

PMid:21396241

43. Chisolm DJ, Purnell TS, Cohen DM, McAlearney AS. Clinician perceptions of an electronic medical record during the first year of implementaton in emergency services. Pediatr Emerg Care. 2010;26(2):107-10. https://doi.org/10.1097/ pec.0b013e3181ce2f99 PMid:20093997

44. Morton ME, Wiedenbeck S. EHR Acceptance Factors in Ambulatory Care: A Survey of Physician Perceptions. United States: Perspectives in Health Information Management/ AHIMA, American Health Information Management Association; 2010. p. 7.

45. Carayon P, Cartmill R, Blosky MA, Brown R, Hackenberg M, Hoonakker $\mathrm{P}$, et al. ICU nurses' acceptance of electronic health records. J Am Med Inform Assoc. 2011;18(6):812-9. PMid:21697291

46. Holtz B, Krein S. Understanding nurse perceptions of a newly implemented electronic medical record system. J Technol Hum Serv. 2011;29(4):247-62. https://doi.org/10.1080/15228835.201 1.639931

47. Aggelidis VP, Chatzoglou PD. Hospital information systems: Measuring end user computing satisfaction (EUCS). J Biomed Inform. 2012;45(3):566-79. https://doi.org/10.1016/j. jbi.2012.02.009

PMid:22426283

48. Schnall R, Smith AB, Sikka M, Gordon P, Camhi E, Kanter T, et al. Employing the FITT framework to explore HIV case managers' perceptions of two electronic clinical data (ECD) summary systems. Int J Med Inform. 2012;81(10):e56-62. https://doi.org/10.1016/j.ijmedinf.2012.07.002

49. Lin C, Lin IC, Roan J. Barriers to physicians' adoption of healthcare information technology: An empirical study on multiple hospitals. J Med Syst. 2012;36(3):1965-77. https://doi. org/10.1007/s10916-011-9656-7 PMid:21336605

50. Dale JA, Behkami NA, Olsen GS, Dorr DA. A multi-perspective analysis of lessons learned from building an integrated care coordination information system (ICCIS). AMIA Annu Symp Proc. 2012;2012:129-35. PMid:23304281

51. Bouamrane MM, Mair FS. A study of general practitioners' perspectives on electronic medical records systems in
NHSScotland. BMC Med Inform Decis Mak. 2013;13:58. https:// doi.org/10.1186/1472-6947-13-58

PMid:23688255

52. Messeri P, Khan S, Millery M, Campbell A, Merrill J, Shih S, et al. An information systems model of the determinants of electronic health record use. Appl Clin Inform. 2013;4(2):185-200. https:// doi.org/10.4338/aci-2013-01-ra-0005

PMid:23874357

53. Hsu SC, Liu CF, Weng RH, Chen CJ. Factors influencing nurses' intentions toward the use of mobile electronic medical records. Comput Inform Nurs. 2013;31(3):124-32. https://doi. org/10.1097/nxn.0b013e318270100b

PMid:23114391

54. Michel-Verkerke MB, Hoogeboom AM. Evaluation of the USE IT-questionnaire for the evaluation of the adoption of electronic patient records by healthcare professionals. Methods Inf Med. 2013;52(3):189-98. https://doi.org/10.3414/me12-01-0041 PMid:23591761

55. Mei YY, Marquard J, Jacelon C, DeFeo AL. Designing and evaluating an electronic patient falls reporting system: Perspectives for the implementation of health information technology in long-term residential care facilities. Int J Med Inform. 2013;82(11):e294-306. https://doi.org/10.1016/j. ijmedinf.2011.03.008 PMid:21482183

56. Gardner CL, Pearce PF. Customization of electronic medical record templates to improve end-user satisfaction. Comput Inform Nurs. 2013;31(3):115-21. https://doi.org/10.1097/ nxn.0b013e3182771814 PMid:23321480

57. Gu Y, Day K. Propensity of people with long-term conditions to use personal health records. Stud Health Technol Inform. 2013;188:46-51.

PMid:23823287

58. Kuo KM, Liu CF, Ma CC. An investigation of the effect of nurses' technology readiness on the acceptance of mobile electronic medical record systems. BMC Med Inform Decis Mak. 2013;13(1):88. https://doi.org/10.1186/1472-6947-13-88 PMid:23938040

59. Tavakoli N, Jahanbakhsh M, Shahin A, Mokhtari H, Rafiei M. Electronic medical record in central polyclinic of isfahan oil industry: A case study based on technology acceptance model. Acta Inform Med. 2013;21(1):23-5. https://doi.org/10.5455/ aim.2012.21.23-25 PMid:23572857

60. Kirkendall ES, Goldenhar LM, Simon JL, Wheeler DS, Andrew Spooner S. Transitioning from a computerized provider order entry and paper documentation system to an electronic health record: Expectations and experiences of hospital staff. Int $\mathrm{J}$ Med Inform. 2013;82(11):1037-45. https://doi.org/10.1016/j. ijmedinf.2013.08.005

PMid:24041453

61. Iqbal U, Ho CH, Li YC, Nguyen PA, Jian WS, Wen HC. The relationship between usage intention and adoption of electronic health records at primary care clinics. Comput Methods Programs Biomed. 2013;112(3):731-7. https://doi.org/10.1016/j. cmpb.2013.09.001

PMid:24091088

62. Bossen C, Jensen LG, Udsen FW. Evaluation of a comprehensive EHR based on the DeLone and McLean model for IS success: Approach, results, and success factors. Int $J$ Med Inform. 2013;82(10):940-53. https://doi.org/10.1016/j. ijmedinf.2013.05.010

PMid:23827768

63. $\mathrm{Ho} \mathrm{CH}$, Wene $\mathrm{HC}$, Chu CM, Wu YS, Wang JL. 
Importance-satisfaction analysis for primary care physicians' perspective on EHRs in Taiwan. Int J Environ Res Public Health. 2014;11(6):6037-51.

PMid:24914640

64. Hysong SJ, Spitzmuller C, Espadas D, Sittig DF, Singh H. Electronic alerts and clinician turnover: The influence of user acceptance. Am J Manag Care. 2014;20(17):SP520-30. PMid:25811826

65. Schwarz C, Schwarz A. To adopt or not to adopt: A perceptionbased model of the EMR technology adoption decision utilizing the technology-organization-environment framework. J Organ End User Comput. 2014;26(4):57-79. https://doi.org/10.4018/ joeuc. 2014100104

66. Liu CF, Cheng TJ. Exploring critical factors influencing physicians' acceptance of mobile electronic medical records based on the dual-factor model: A validation in Taiwan. BMC Med Inform Decis Mak. 2015;15:4. https://doi.org/10.1186/ s12911-014-0125-3

PMid:25889506

67. Kralj D, Kern J, Tonkovic S, Koncar M. Development of the quality assessment model of EHR software in family medicine practices: Research based on user satisfaction. J Innov Health Inform. 2015;22(3):340-58. https://doi.org/10.14236/jhi. v22i3.158 PMid:26577425

68. Wang JY, Ho HY, Chen JD, Chai S, Tai CJ, Chen YF. Attitudes toward inter-hospital electronic patient record exchange: Discrepancies among physicians, medical record staff, and patients. BMC Health Serv Res. 2015;15:264. https://doi. org/10.1186/s12913-015-0896-y

69. Sintonen S, Mäkelä K, Miettinen R. User acceptance of electronic health records: A post-implementation study. Int J Healthc Technol Manage. 2015;15(2):162-75. https://doi. org/10.1504/ijhtm.2015.074556
70. Gan Q. Is the adoption of electronic health record system contagious? Health Policy Technol. 2015;4(2):107-12. https:// doi.org/10.1016/j.hlpt.2015.02.009

71. Salleh MI, Zakaria N, Abdullah R. The influence of system quality characteristics on health care providers' performance: Empirical evidence from Malaysia. J Infect Public Health. 2016;9(6):698707. https://doi.org/10.1016/j.jiph.2016.09.002 PMid:27659115

72. Kim S, Lee $\mathrm{KH}$, Hwang $\mathrm{H}$, Yoo $\mathrm{S}$. Analysis of the factors influencing healthcare professionals' adoption of mobile electronic medical record (EMR) using the unified theory of acceptance and use of technology (UTAUT) in a tertiary hospital. BMC Med Inform Decis Mak. 2016;16(1):12. https:// doi.org/10.1186/s12911-016-0249-8

PMid:26831123

73. Shaw NT. CHEATS: A generic information communication technology (ICT) evaluation framework. Comput Biol Med. 2002;32(3):209-20. PMid: 11922936

74. Alharthi H, Youssef A, Radwan S, Al-Muallim S, Zainab AT. Physician satisfaction with electronic medical records in a major Saudi government hospital. J Taibah Univ Med Sci. 2014;9(3):213-8. https://doi.org/10.1016/j.jtumed.2014.01.004

75. Ajzen I. The theory of planned behavior. Organ Behav Hum Decis Proc. 1991;50(2):179-211. https://doi. org/10.1016/0749-5978(91)90020-t

76. Angst CM, Agarwal R, Sambamurthy V, Kelley K. Socia contagion and information technology diffusion: The adoption of electronic medical records in US hospitals. Manage Sci. 2010;56(8):1219-41. https://doi.org/10.1287/mnsc.1100.1183

77. Michel-Verkerke MB, Stegwee RA, Spil TA. The six P's of the next step in electronic patient records in the Netherlands. Health Policy Technol. 2015;4(2):137-43. https://doi.org/10.1016/j. hlpt.2015.02.011 


\title{
Appendix 1: Literature review search strategies to identify studies from electronic databases
}

\author{
Search strategy of PubMed
}

((((Hospital Information Systems [MAJR] OR "Hospital Information System*" [TIAB] OR Electronic Health Records [MAJR] OR "Electronic Health Record*" [TIAB] OR Medical Records Systems, Computerized [MAJR] OR "Computerized Medical Records System" Record*" [TIAB]) AND (Evaluation framework [TIAB] OR measurement practice [TIAB] OR evaluation model [TIAB] OR evaluation research [TIAB] OR evaluation studies [TIAB] OR program evaluation [TIAB] OR program methods [TIAB] OR assessment [TIAB] OR accreditation [TIAB] OR certification [TIAB] OR license [TIAB] OR cognitive evaluation [TIAB] OR usability testing [TIAB] OR systems analysis [TIAB] OR software evaluation [TIAB] OR qualitative study [TIAB] OR qualitative evaluation [TIAB] OR focus groups [TIAB] OR questionnaires [TIAB] OR questionnaires [TIAB] OR interviews [TIAB] OR taxonomy [TIAB] OR classification [TIAB] OR balanced scorecard health care outcome [TIAB] OR health care process assessment [TIAB] OR cost-benefit analysis [TIAB] OR health services research))) AND ("last 10 years"[PDat] AND Humans [Mesh] AND English[lang])

Search strategy of ScienceDirect

TITLE-ABSTR-KEY (Electronic Health Records OR Electronic Medical Record OR Hospital information systems OR Electronic Patient Records) and TITLE-ABSTR-KEY (Evaluation framework OR measurement practice $O R$ evaluation model $O R$ evaluation research OR evaluation studies OR program evaluation OR program methods OR assessment OR accreditation OR measure OR certification OR license OR cognitive evaluation OR systems analysis OR software evaluation OR qualitative study OR qualitative evaluation OR focus groups OR questionnaires OR questionnaires OR interviews OR taxonomy OR classification OR balanced scorecard health care outcome OR health care process assessment) (All Sources[Computer Science, Medicine, and Dentistry]).

Search strategy of Cochran

1\# (Electronic patient record OR Electronic Health Record OR Hospital Information System OR Electronic medical Record):ti,ab

2\# Assess OR Evaluation OR Measure OR accredit OR license OR certify

3\# \#1 and \#2

Search strategy of Scopus

Title, abstract, keywords: ([Hospital Information Systems OR Electronic Health Record OR Electronic Patient Record OR Electronic Medical Record] AND [Evaluation framework OR measurement practice OR evaluation model OR evaluation research OR evaluation studies OR program evaluation OR program methods OR assessment OR accreditation OR measure OR certification OR license OR cognitive evaluation OR systems analysis OR software evaluation OR qualitative study OR qualitative evaluation OR focus groups OR questionnaires OR questionnaires OR interviews OR taxonomy OR classification OR balanced scorecard health care outcome OR health care process assessment]) 
Appendix 2: The relative frequency of evaluation measures in technology aspect

\begin{tabular}{|c|c|c|c|c|c|}
\hline System quality & References & Information quality & References & Service quality & References \\
\hline Ease of Use (0.61), & $\begin{array}{l}\text { [3], [4], [5], [12], [24], [27], } \\
{[28],[31],[32],[33],[34],[36],} \\
{[38],[40],[41],[43],[46],[52],} \\
\text { [54], [57], [58], [59], [61], [66], } \\
\text { [70], [72] }\end{array}$ & Accuracy $(0.21)$ & $\begin{array}{l}\text { [3], [4], [5], [9], [20], [22], [25], } \\
{[31],[39],[47],[60],[70],[74]}\end{array}$ & Training (0.16) & $\begin{array}{l}\text { [9], [12], [41], [44], [46], } \\
\text { [47], [48], [64], [70], [74] }\end{array}$ \\
\hline Usefulness $(0.52)$ & $\begin{array}{l}{[3],[4],[5],[9],[20],[24],[27],} \\
{[28],[29],[31],[32],[33],[34],} \\
{[35],[36],[38],[39],[40],[41],} \\
{[43],[43],[43],[44],[45],[46],} \\
{[47],[52],[53],[54],[55],[57],} \\
\text { [58], [59], [61], [62], [66], [70], } \\
\text { [71], [72], [74] }\end{array}$ & Completeness $(0.18)$ & $\begin{array}{l}\text { [2], [3], [5], [9], [19], [20], [22], } \\
{[26],[29],[31],[74]}\end{array}$ & Responsiveness $(0.10)$ & $\begin{array}{l}{[4],[19],[22],[29],[52],} \\
{[70]}\end{array}$ \\
\hline Usability (0.21) & $\begin{array}{l}{[2],[19],[20],[25],[26],[29],} \\
{[31],[47],[54],[56],[67]}\end{array}$ & Timeliness (0.13) & $\begin{array}{l}\text { [3], [4], [5], [20], [31], [38], } \\
{[39],[47]}\end{array}$ & Assurance $(0.13)$ & $\begin{array}{l}{[4],[19],[20],[22],[29],} \\
{[41],[52],[63]}\end{array}$ \\
\hline Reliability (0.21) & $\begin{array}{l}{[2],[4],[5],[9],[25],[26],[29],} \\
{[39],[52],[54],[67],[69],[70]}\end{array}$ & Format $(0.13)$ & $\begin{array}{l}{[4],[5],[9],[22],[29],[39],} \\
{[47],[74]}\end{array}$ & Empathy $(0.08)$ & [4], [9], [19], [20], [70] \\
\hline Response time $(0.13)$ & $\begin{array}{l}{[20],[22],[29],[47],[56],[62],} \\
{[63],[74]}\end{array}$ & Sufficiently (0.11) & $\begin{array}{l}\text { [4], [9], [22], [39], [52], [62], } \\
{[70]}\end{array}$ & $\begin{array}{l}\text { IT staffs availability and providing } \\
\text { IT support }(0.10)\end{array}$ & $\begin{array}{l}\text { [24], [28], [29], [34], } \\
\text { [43], [74] }\end{array}$ \\
\hline Accessibility $(0.10)$ & {$[4],[9],[29],[50],[63],[67]$} & Ease of use $(0.10)$ & [2], [4], [25], [26], [62], [70] & Pay attention to user needs $(0.05)$ & {$[9],[19],[29]$} \\
\hline Sufficient resources $(0.19)$ & $\begin{array}{l}{[2],[9],[22],[24],[25],[26],} \\
{[28],[34],[43],[46],[48],[71]}\end{array}$ & Availability $(0.06)$ & [20], [29], [52], [74] & $\begin{array}{l}\text { System guideline or users' manual } \\
(0.03)\end{array}$ & [22], [62] \\
\hline Availability (0.08) & [2], [25], [26], [39], [65] & Accessibility $(0.05)$ & [19], [22], [70], [77] & Assistance (0.02) & [70] \\
\hline System function $(0.06)$ & [50], [63], [67], [68] & Legibility $(0.05)$ & [3], [31], [60] & Follow-up service (0.02) & [32] \\
\hline $\begin{array}{l}\text { System interoperability and } \\
\text { integration }(0.15)\end{array}$ & $\begin{array}{l}\text { [4], [9], [28], [29], [34], [43], } \\
{[46],[67],[71]}\end{array}$ & Reliability (0.05) & [3], [19], [29] & Reliability $(0.02)$ & [4] \\
\hline Complexity $(0.03)$ & [53], [69] & Relevance (0.05) & [3], [31], [74] & IS performance (0.02) & [70] \\
\hline Flexibility $(0.02)$ & [4] & Consistency (0.03) & [3], [31] & & \\
\hline Mobility (0.02) & [66] & Compatibility (0.05) & [5], [20], [70] & & \\
\hline \multirow[t]{9}{*}{ Confusion (0.02) } & [70] & Clear (0.03) & [4], [39] & & \\
\hline & & Currency $(0.03)$ & [5], [70] & & \\
\hline & & Content $(0.02)$ & [47] & & \\
\hline & & $\begin{array}{l}\text { Secure and confidential } \\
(0.02)\end{array}$ & [29] & & \\
\hline & & Right data $(0.02)$ & [70] & & \\
\hline & & Right level of detail (0.02) & [70] & & \\
\hline & & Locatability (0.02) & [70] & & \\
\hline & & Meaning (0.02) & [70] & & \\
\hline & & Authorization (0.02) & [70] & & \\
\hline
\end{tabular}

RF: Relative frequency.

Appendix 3: The relative frequency of evaluation measures in human aspect

\begin{tabular}{|c|c|c|c|c|c|}
\hline Users' Satisfaction & $\operatorname{RF}(\%)^{*}$ & References & Users characteristics and personality & $\operatorname{RF}(\%)^{*}$ & References \\
\hline Satisfaction & 0.29 & $\begin{array}{l}\text { [2], [19], [20], [21], [22], [25], [26], [29], [30], [33], [39], } \\
{[43],[47],[51],[52],[54],[59],[64]}\end{array}$ & General characteristics & 0.13 & $\begin{array}{l}\text { [3], [19], [23], [35], [39], } \\
{[68],[71]}\end{array}$ \\
\hline Attitude toward system & 0.18 & [19], [23], [24], [28], [33], [34], [35], [36], [44], [48], [72] & Personal identity & 0.02 & [27] \\
\hline System acceptance & 0.11 & {$[3],[4],[5],[31],[32],[45],[55]$} & Innovativeness & 0.02 & [58] \\
\hline Users expectations & 0.05 & {$[29],[33],[37]$} & Maximum Coverage & 0.16 & \\
\hline Personality traits & 0.02 & [35] & $\begin{array}{l}\text { Positive or negative feeling about } \\
\text { EHR }\end{array}$ & & \\
\hline Maximum coverage & 0.65 & & Concerns for EHR & 0.10 & {$[2],[23],[25],[26],[54],[68]$} \\
\hline System use & $\operatorname{RF}(\%)^{*}$ & References & Perceived threat & 0.03 & {$[49],[66]$} \\
\hline (Behavioral) Intention of use & 0.34 & $\begin{array}{l}\text { [23], [24], [27], [28], [29], [33], [34], [35], [36], [42], [49], } \\
\text { [53], [57], [58], [59], [61], [64], [66], [68], [69], [72] }\end{array}$ & Perceived risk & 0.02 & {$[24]$} \\
\hline System use & 0.19 & $\begin{array}{l}\text { [12], [20], [21], [22], [34], [35], [36], [51], [59], [62], } \\
{[69],[72]}\end{array}$ & Instructional trust $(\mathrm{n}=1)$ & 0.02 & [24] \\
\hline Frequency of use & 0.05 & {$[29],[30],[39]$} & Optimism & 0.02 & [58] \\
\hline Intensity of use & 0.02 & [29] & Discomfort & 0.02 & [58] \\
\hline Level of use & 0.02 & [20] & Anxiety & 0.02 & [28] \\
\hline Reason to use & 0.02 & [68] & Insecurity & 0.02 & [58] \\
\hline Observability & 0.02 & [53] & Inequity & 0.02 & [49] \\
\hline Information about change & 0.02 & [27] & Resistance to change & 0.02 & [27] \\
\hline Trialability & 0.02 & [53] & & & \\
\hline Computer knowledge and Self-efficacy & $\operatorname{RF}(\%)^{*}$ & References & & & \\
\hline Self-efficacy & 0.13 & {$[5],[24],[27],[28],[32],[36],[43],[61]$} & & & \\
\hline
\end{tabular}


Appendix 4: The relative frequency of evaluation measures in organization aspect

\begin{tabular}{|c|c|c|c|c|c|c|c|c|}
\hline \multirow{2}{*}{$\begin{array}{l}\text { Characteristics of organization and } \\
\text { Organizational factors } \\
\text { Social context }\end{array}$} & \multirow{2}{*}{$\begin{array}{l}\text { RF }(\%)^{*} \\
0.21\end{array}$} & \multirow{2}{*}{$\begin{array}{l}\text { References } \\
{[9],[23],[24],[27],[28],[34],} \\
{[35],[41],[43],[46],[61],} \\
{[70],[72]}\end{array}$} & \multirow{2}{*}{$\begin{array}{l}\text { Effects on workflow and } \\
\text { organization } \\
\text { Team communication }\end{array}$} & \multirow{2}{*}{$\begin{array}{l}\operatorname{RF}(\%)^{*} \\
0.08\end{array}$} & \multirow{2}{*}{$\begin{array}{l}\text { References } \\
{[2],[19],[25],} \\
{[26],[50]}\end{array}$} & \multirow{2}{*}{$\begin{array}{l}\text { Effects on outcome } \\
\text { quality of care RF }(\%)^{*} \\
\text { Patient safety }\end{array}$} & \multicolumn{2}{|c|}{ References } \\
\hline & & & & & & & 0.08 & $\begin{array}{l}\text { [2], [25], [26], } \\
{[37],[60]}\end{array}$ \\
\hline $\begin{array}{l}\text { Compatibility and fitness with the } \\
\text { work process }\end{array}$ & 0.18 & $\begin{array}{l}{[5],[9],[24],[32],[38],[40],} \\
{[47],[48],[53],[54],[71]}\end{array}$ & $\begin{array}{l}\text { Unintended consequences, } \\
\text { barriers }\end{array}$ & 0.08 & $\begin{array}{l}\text { [2], [25], [26], } \\
{[35],[37]}\end{array}$ & $\begin{array}{l}\text { Doctor-patient } \\
\text { relationship }\end{array}$ & 0.04 & [2], [25], [26] \\
\hline Management support & 0.08 & {$[5],[12],[20],[32],[44]$} & $\begin{array}{l}\text { Appropriate patient care } \\
\text { orders }\end{array}$ & 0.04 & {$[2],[26],[47]$} & Costs & 0.04 & [12], [44], [60] \\
\hline Physician involvement & 0.03 & [12], [44] & Department involvement & 0.04 & [2], [26], [47] & Patient knowledge & 0.04 & [2], [25], [26] \\
\hline Organization characteristics & 0.05 & {$[19],[53],[65]$} & $\begin{array}{l}\text { Users' productivitylprovider } \\
\text { performance }\end{array}$ & 0.03 & [29], [71] & Patient outcomes & 0.04 & [2], [25], [26] \\
\hline Physician autonomy & 0.03 & [12], [44] & $\begin{array}{l}\text { Research and hospital } \\
\text { image }\end{array}$ & 0.03 & [19], [77] & Impact on patient care & 0.02 & [19], [37] \\
\hline Communication & 0.03 & [20], [38] & Individual impact & 0.03 & [51], [52] & Self-management & 0.01 & [77] \\
\hline Organization Structure & 0.03 & [20], [21] & Clinician involvement & 0.03 & [2], [26] & Communication & 0.01 & [77] \\
\hline Coherence & 0.02 & [51] & Product effectiveness & 0.03 & [20], [63] & Privacy & 0.01 & [77] \\
\hline Cognitive participation & 0.02 & [51] & Demonstrability of results & 0.01 & [27] & Maximum coverage & 0.37 & \\
\hline Collective action & 0.02 & [51] & Efficiency & 0.01 & [20] & Environment & 0.08 & $\begin{array}{l}\text { [20], [21], [24], } \\
\text { [37], [65] }\end{array}$ \\
\hline Reflexive monitoring & 0.02 & [51] & Relative advantage & 0.01 & [53] & & & \\
\hline Monitoring and feedback & 0.02 & [64] & $\begin{array}{l}\text { Provider perceptions of } \\
\text { value }\end{array}$ & 0.01 & [64] & & & \\
\hline Leadership & 0.02 & [38] & Global outcome & 0.01 & [19] & & & \\
\hline Physical proximity & 0.02 & [70] & Hospital profile & 0.01 & [19] & & & \\
\hline Competition & 0.02 & [20] & Stakeholder benefit & 0.01 & [23] & & & \\
\hline $\begin{array}{l}\text { Employee understanding and } \\
\text { support of implementation }\end{array}$ & 0.03 & [37], [60] & Inter-hospital access & 0.01 & [29] & & & \\
\hline $\begin{array}{l}\text { Organizational support for } \\
\text { implementation }\end{array}$ & 0.02 & [60] & $\begin{array}{l}\text { Documentation quality } \\
\text { standards }\end{array}$ & 0.01 & [9] & & & \\
\hline Innovative culture in hospital & 0.02 & [38] & $\begin{array}{l}\text { Quality of patient data } \\
\text { in EMR }\end{array}$ & 0.01 & [38] & & & \\
\hline Open culture in hospital & 0.02 & [38] & Inter-hospital access & 0.01 & [29] & & & \\
\hline Situational normality & 0.02 & [24] & & & & & & \\
\hline Strategy & 0.02 & [20] & & & & & & \\
\hline Supporting best practices & 0.02 & [50] & & & & & & \\
\hline Supportive norms & 0.02 & [64] & & & & & & \\
\hline Task equivocality & 0.02 & [70] & & & & & & \\
\hline Task interdependence & 0.02 & [41] & & & & & & \\
\hline Caseload & 0.02 & {$[70]$} & & & & & & \\
\hline Voluntary turnover & 0.02 & [64] & & & & & & \\
\hline
\end{tabular}

Voluntary turnover 